\section{PRIMERAS POLÍTICAS DE VIVIENDA EN ESPAÑA Y SU INFLUENCIA EN LA EVOLUCIÓN DE LA TIPOLOGÍA RESIDENCIAL: EL CASO DE BENALÚA (1883-1956)}

Raquel Pérez del Hoyo y María Elia Gutiérrez $\mathrm{MozO}^{2}$

\section{Resumen}

El estudio del proceso de adaptación tipológica de las arquitecturas residenciales del barrio de Benalúa, una de las áreas consolidadas más singulares de la ciudad de Alicante (España), constituye un ejemplo clave para entender el alcance que tuvieron las primeras políticas de vivienda aplicadas en ese país, con anterioridad a la redacción de los Planes Generales que, en el transcurso del siglo $\mathrm{XX}$, fueron ordenando las ciudades españolas y que en el caso de Alicante coincidió con la aprobación de la primera Ley del Suelo estatal (1956). De su análisis se obtienen las conclusiones que identifican los procedimientos que, por cambios

\section{FIRST HOUSING POLICIES IN SPAIN AND THEIR INFLUENCE ON THE EVOLUTION OF RESIDENTIAL TYPOLOGY: THE CASE OF BENALÚA (1883-1956)}

Raquel Pérez del Hoyo ${ }^{1}$, María Elia Gutiérrez $\mathrm{MozO}^{2}$

\section{Abstract}

The study of the typological adaptation process of residential architecture in Benalúa neighborhood, a unique consolidated area located in Alicante (Spain), is a key factor to understand the scope of the first housing policies implemented in Spain prior to the drafting of the General Plans back in the twentieth century. Such an initiative was put into action in 1956, along with the enactment of the first Land Bill of the country. This paper identifies the processes that, due to social, political or regulatory changes or pressure from the real estate market, defined the evolution of housing for over seven decades. Today, the consequences 
sociales, políticos, de normativa o presión del mercado inmobiliario, condicionaron la evolución de la vivienda durante siete décadas, huellas que en la actualidad vienen desapareciendo a un ritmo vertiginoso, constatando el grado de intervención del Estado y de los municipios, así como su influencia y responsabilidad en la determinación de los tipos edificatorios.

\section{PALABRAS CLAVE: POLÍTICAS DE VIVIENDA, EVOLUCIÓN TIPOLÓGICA, AROUITECTURA RESIDENCIAL, BARRIOS OBREROS, ESTADO SOCIAL}

Fecha de recepción: 31-10-2012

Fecha de aceptación: 13-06-2013

1 España. Arquitecta, Doctora en Arquitectura. Profesora Asociada de la Escuela Politécnica Superior de la Universidad de Alicante. Correo electrónico: perezdelhoyo@ua.es

2 España. Arquitecta. Doctora en Arquitectura. Profesora Contratada de la Escuela Politécnica Superior de la Universidad de Alicante.Correo electrónico: eliagmozo@ua.es of this event have almost disappeared, confirming the intervention and influence of the State and municipalities on the determination of building types.

KEYWORDS: HOUSING POLICIES, TYPOLOGICAL EVOLUTION, RESIDENTIAL ARCHITECTURE, WORKING-CLASS NEIGHBORHOODS, SOCIAL STATE.
Received: 31-10-2012

Accepted: 13-06-2013

1 Spain. Architect. PhD in Architecture. Associate Professor, Polytechnic University College, University of Alicante. Email: perezdelhoyo@ua.es

2 Spain. Architect. PhD in Architecture. Professor, Polytechnic University College, University of Alicante. Email: eliagmozo@ ua.es 


\section{Introducción}

En 1859, Ildefonso Cerdá abrió el debate sobre la pésima situación de la vivienda en España con la propuesta del Proyecto de Reforma y Ensanche de Barcelona ${ }^{3}$. A partir de entonces, aludiendo al modo más avanzado con que se venía afrontando el problema en las naciones europeas más industrializadas, sobre todo en la vecina Francia con el emblemático referente de la Cité Ouvrière de Mulhouse proyectada por Muller en 1853, se sucedieron en el país una serie de estudios ${ }^{4}$ que se intensificaron desde la Exposición Universal celebrada en París, en 1867. Pero fue después, con cierto retraso, en el primer Congreso Nacional de Arquitectos celebrado en Madrid, en 1881, cuando en España se asumió realmente la necesidad de debatir sobre la conveniencia, o no, de la construcción de barrios obreros frente a otros sistemas mixtos de estratificación social que en Europa ya habían sido prácticamente desechados ${ }^{5}$. A favor, las propuestas de Mariano Belmás, Secretario de la Sociedad Central de Arquitectos (SCA) ${ }^{6}$, sobre tipologías arquitectónicas mínimas y métodos para economizar

3 Cerdá, 1859.

4 Cerdá, 1867; Fernández, 1868; Rebolledo, 1872; Casas, 1874.

5 Sociedad Central de Arquitectos, 1883a.

6 La "Asociación de Arquitectos" (Madrid, 1849), que transcurrido un año pasó a denominarse "Sociedad Central de Arquitectos", constituye el precedente inmediato de los actuales Colegios Oficiales de Arquitectos en España. su construcción ${ }^{7}$, y el avanzado modelo de Ciudad Lineal desarrollado a partir de 1882 por Arturo Soria para el extrarradio de $\mathrm{Madrid}^{8}$, de algún modo antecedente de la Garden City planteada por Howard en $1989^{9}$, constituyeron el marco teórico de referencia español, alternativo a los sistemas de clasificación social y paliativo de las desigualdades que, en la mayoría de las ciudades, llegó a generar el modelo de ensanche.

Paralelamente, la SCA se sumaba al debate recurrente en la Europa desarrollada sobre la intervención pública, sobre si el deber de procurar viviendas cómodas y sanas correspondía al Estado o a los municipios y si debían éstos convertirse en constructores o abrir caminos a la empresa privada ${ }^{10}$. Con especial interés se estudiaba la propuesta que se debatía en Francia para solucionar el problema parisino y que consistía en avalar, el Ayuntamiento y los créditos solicitados por los propietarios del suelo, en caso de reservar parte de las construcciones como casas baratas o viviendas de alquiler económico. No se trataba de subvencionar sino de alentar y estimular la iniciativa privada, aliviando además las construcciones de cargas y tributos. La

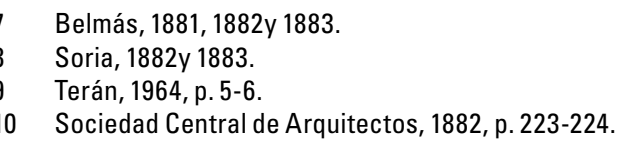

10 Sociedad Central de Arquitectos, 1882, p. 223-224. 
opinión mayoritaria del momento defendía extender la propuesta de París al resto de los municipios del territorio, evitando así la mediación directa del Estado $^{11}$.

En España, sin embargo, sólo llegó a aplicarse una versión sesgada de la propuesta parisina. Si bien, con el apoyo de las administraciones públicas, la creación de sociedades para la construcción de casas económicas fue extendiéndose desde el ámbito patronal al empresarial, estas primeras ayudas o políticas de vivienda, impulsadas únicamente desde los gobiernos locales y no desde las administraciones del Estado, se centraron exclusivamente en permitir cierto incentivo económico con la exención de tributos o impuestos. Ni siquiera se detallaron normativas o condiciones higiénicas mínimas para este tipo de actuaciones, a pesar de que la SCA había difundido los pronunciamientos de Gran Bretaña que planteaba comenzar a imponer por ley, a los propietarios, los alquileres y las condiciones de habitabilidad dignas ${ }^{12}$.

La debilidad del modelo español permitió a las clases más favorecidas seguir dirigiendo la situación en un periodo de fuerte expansión económica para el país. De hecho, en las acciones desarrolladas en la transición del siglo XIX al XX, al problema de la especulación, realidad que se evidenció tanto

11 Sociedad Central de Arquitectos, 1883b, p. 96.

12 Sociedad Central de Arquitectos, 1883c, p. 270-271. en las reformas interiores (con las desamortizaciones y plusvalías) como en los ensanches de las ciudades (con las recalificaciones de terrenos), se sumó el interés de los estatus más pudientes por evitar un posible levantamiento de las clases más humildes. La vivienda social se planteaba, por tanto, como medio para resolver las demandas de la población, a la vez que encubría y justificaba la especulación y el control que ejercían propietarios y constructores.

Progresivamente, el asociacionismo o cooperativismo fue instalándose como modelo alternativo, aunque lógicamente con mayores dificultades, sobre todo en la obtención de capitales iniciales. Los asociados o accionistas asumían el compromiso de abonar ciertas cuotas en concepto de alquiler durante la construcción, proceso que solía demorarse, adquiriendo al fin un derecho de compra sobre la vivienda, habitualmente otorgada por sorteo. Alcanzar el derecho de propiedad suponía, sin duda, uno de los mayores logros para la clase proletaria, aunque resultara ser un mecanismo más de la burguesía para contener posibles sediciones ${ }^{13}$.

En este contexto inicial de intervención pública prácticamente testimonial que caracterizó a la España del último tercio del siglo XIX, debe entenderse la relevancia de la actuación de Benalúa de

13 Castrillo, 2001. 
Alicante $^{14}$, un buen ejemplo de iniciativa privada que llegó a convertirse en referente nacional, basado en la combinación de los dos modelos descritos: empresarial y cooperativo. Fundamentando su idoneidad en el discurso recurrente de la vivienda obrera y justificándose, además, en el vacío normativo y en la carencia de un plano oficial de ensanche, Benalúa se erigió como alternativa privada, liderada por la Sociedad Anónima Los Diez Amigos (SLDA) y refrendada por 200 accionistas, a la ineficaz gestión municipal de la época, limitándose el Ayuntamiento a declarar la construcción exenta del pago del arbitrio correspondiente "... por tener que reportar, en su día, beneficios a los intereses municipales e importancia a la población" 15 .

El proyecto de Benalúa fue redactado en 1883 por el arquitecto José Guardiola, reconocido profesional de ideología higienista y precursor del ensanche de Alicante ${ }^{16}$. Precisamente, en el mismo año en que fueron creados, en España y Francia, organismos encargados de recabar información sobre la precariedad de la vivienda obrera ${ }^{17}$. En el caso de España se trató de la primera institución estatal para llevar a cabo programas sociales: una comisión para el estudio

14 En relación al cuerpo teórico-conceptual que documenta la importancia y representatividad del caso de estudio de Benalúa, puede consultarse la Tesis doctoral: Pérez, 2010.

15 Archivo Histórico Municipal de Alicante, 1884.

16 Guardiola, 1895, 1897 y 1909.

17 Arias, 2003, p. 48. de la mejora y bienestar de las clases obreras con el propósito de organizar un congreso nacional para tratar la cuestión, aunque nunca llegó a celebrarse ${ }^{18}$. Benalúa supuso, por tanto, un escenario de ensayo pionero en el país y la oportunidad de llevar a la práctica, aunque de forma sectorial y en la periferia de una ciudad de provincia, las intenciones de un Estado que no lograría intervenir realmente en el problema de la vivienda hasta bien entrado el siglo XX.

\section{El modelo proyectado (1883)}

El barrio se concibió alejado $800 \mathrm{~m}$. hacia el oeste del casco urbano, alcanzando una extensión superficial casi equivalente a la mitad de la ocupada por éste, sobre un llano elevado, próximo al mar, bien comunicado con la población a través de la carretera de Ocaña (Madrid) a Alicante.

Se trató de la primera planificación moderna desarrollada en la ciudad ${ }^{19}$, encabezando los primeros intentos en el país que trataron de concebir y racionalizar el crecimiento urbano. Más allá de reproducir los esquemas establecidos y atendiendo

\footnotetext{
18 Ministerio de la Gobernación, 1883.

19 Giménez, Giner y Varela, 1985, p. 26.
} 
FIGURA 1. PLANO DE ALICANTE 1897. BIBLIOTECA GABRIEL MIRÓ, OBRA SOCIAL DE LA CAJA DE AHORROS DEL MEDITERRÁNEO (CAM).

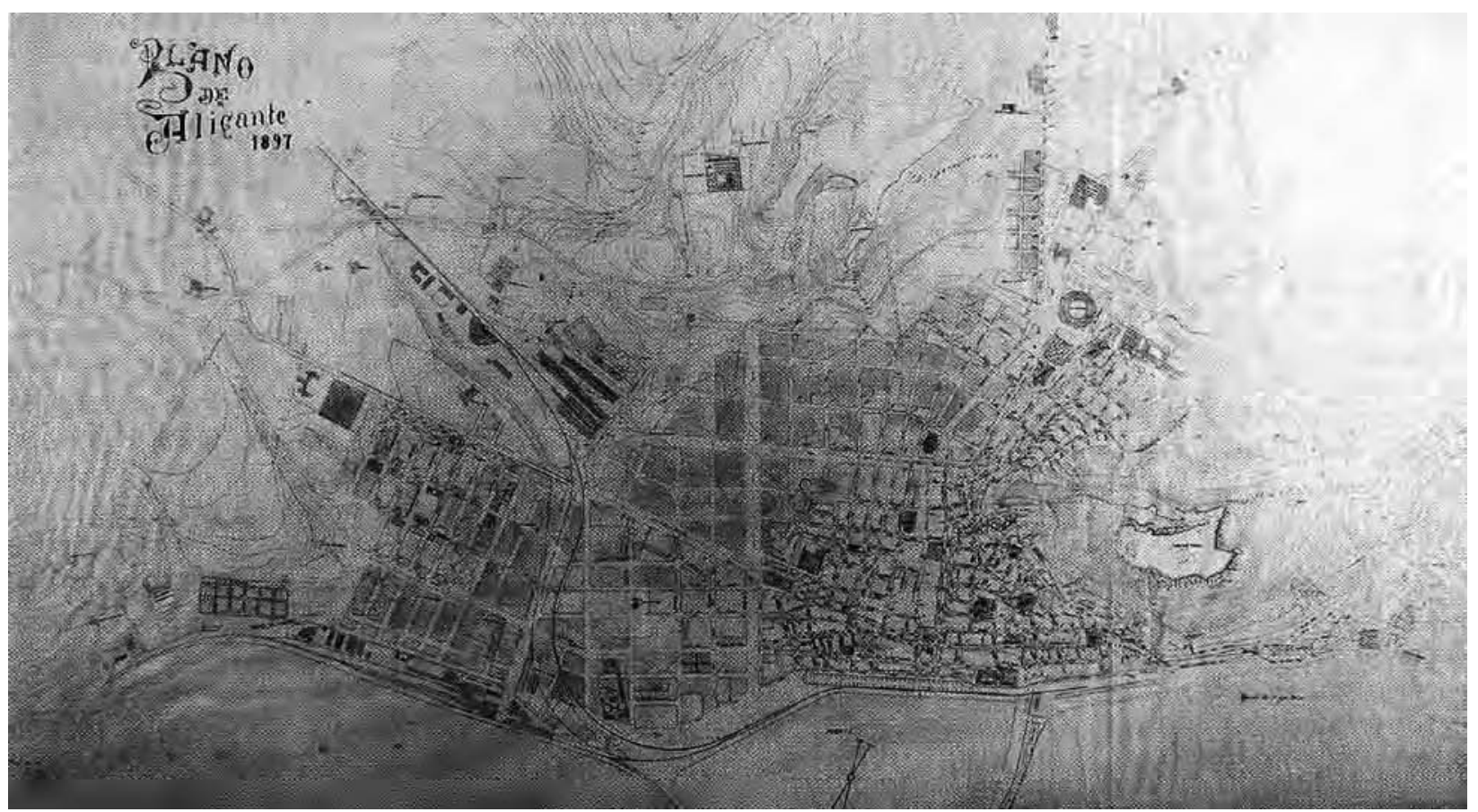

Fuente: Bevià y Varela, 1994, p. 106. 
sobre todo a mejorar sus condiciones higiénicas, la actuación supuso reformular la ciudad antigua ${ }^{20}$, con el planteamiento novedoso de una densidad aproximada de tan sólo ochenta y ocho viviendas por hectárea, frente a las ciento setenta que soportaba el casco urbano ${ }^{21}$.

La propuesta se basaba en el trazado de una retícula ortogonal con la disposición de calles arboladas de 10 y $15 \mathrm{~m}$. de sección, definiendo la formación de manzana rectangulares de 100x40 m. En cada manzana, se parcelaba un rectángulo para contener 14 casas adosadas, con orientación Este-Oeste, dejando las esquinas libres como espacios singulares. Los equipamientos ocupaban manzanas dentro de la trama adecuándose a la ordenación estructural, constituyendo la plaza el lugar de uso público fundamental del barrio ${ }^{22}$.

La planificación de Benalúa estableció sin duda un referente, pero también destacó, con la misma relevancia, su anticipación en el estudio de la problemática de la vivienda. A pesar de responder a una normativa realmente exigua, constituyó uno de los primeros casos en la ciudad que desarrolló un proyecto completo del edificio, concibiendo un modelo terminado de casa para formar un barrio uniforme repitiendo su construcción. Inició,

20 Alonso, Blasco y Piñon, 1990, p. 67 y 69.

21 Calduch y Varela, 1979, p. 53; Giménez, Giner y Varela, op. cit., p. $7,25$.

22 Varela, 1984, p. 21; Calduch y Varela, op. cit., p. 53. por tanto, la aplicación de un urbanismo de ciudad industrial en un momento y lugar de escasa industrialización, favoreciendo en primer término la economía de las obras ${ }^{23}$.

Sobre solares de $10 \mathrm{~m}$. de fachada por $20 \mathrm{~m}$. de fondo, se proyectó un modelo de casa de planta baja y piso para dos viviendas, con accesos independientes desde la vía pública. Este modelo ya había sido empleado en otras planificaciones de carácter más humilde desarrolladas en Alicante. Como antecedente directo del modelo de Benalúa (1883), compuesto de tres crujías paralelas a fachada más patio posterior y tres vanos perpendiculares, se constata el tipo utilizado en el Raval de San Antón (1860)24. La evolución de una a otra tipología vino determinada por la aplicación más avanzada de la ideología higienista al aumentar la dimensión de la parcela, logrando mejores condiciones de iluminación y ventilación. La diferencia entre las viviendas de Benalúa y otras de clase media construidas con anterioridad radicó en este importante incremento de superficie, albergando un total de ocho dependencias: comedor, sala, cuatro alcobas y dos gabinetes, además de cocina y retrete (exterior). La vivienda se proyectó con un fondo aproximado de $13 \mathrm{~m}$., disponiendo patios posteriores con una profundidad aproximada de 7

23 Bevià y Varela, 1994, p. 105.

24 Calduch, 1990, p. 113-114, 116 y 168. 
FIGURA 2.A-PLANOS DEL PROYECTO DE BENALÚA FIRMADOS POR EL AROUITECTO JOSÉ GUARDIOLA, CON FECHA 20 DE OCTUBRE DE 1883. COMPOSICIÓN DE LAS COPIAS PARCIALES CONSERVADAS EN EL ARCHIVO HISTÓRICO MUNICIPAL DE ALICANTE. PROYECTO ORIGINAL DESAPARECIDO.

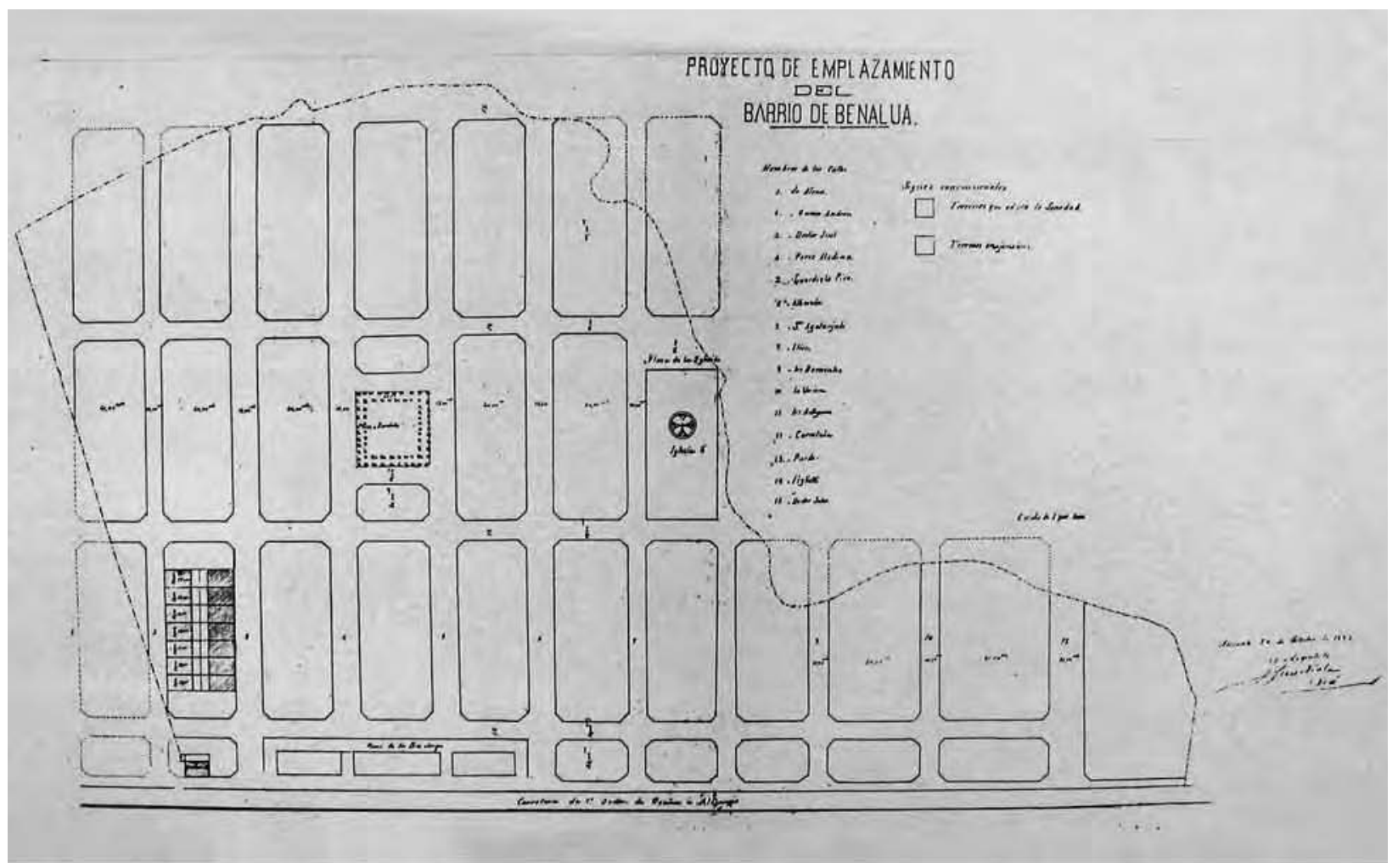

Fuente: Elaboración propia. 
FIGURA 2.B-PLANOS DEL PROYECTO DE BENALÚA FIRMADOS POR EL AROUITECTO JOSÉ GUARDIOLA, CON FECHA 20 DE OCTUBRE DE 1883. COMPOSICIÓN DE LAS COPIAS PARCIALES CONSERVADAS EN EL ARCHIVO HISTÓRICO MUNICIPAL DE ALICANTE. PROYECTO ORIGINAL DESAPARECIDO.
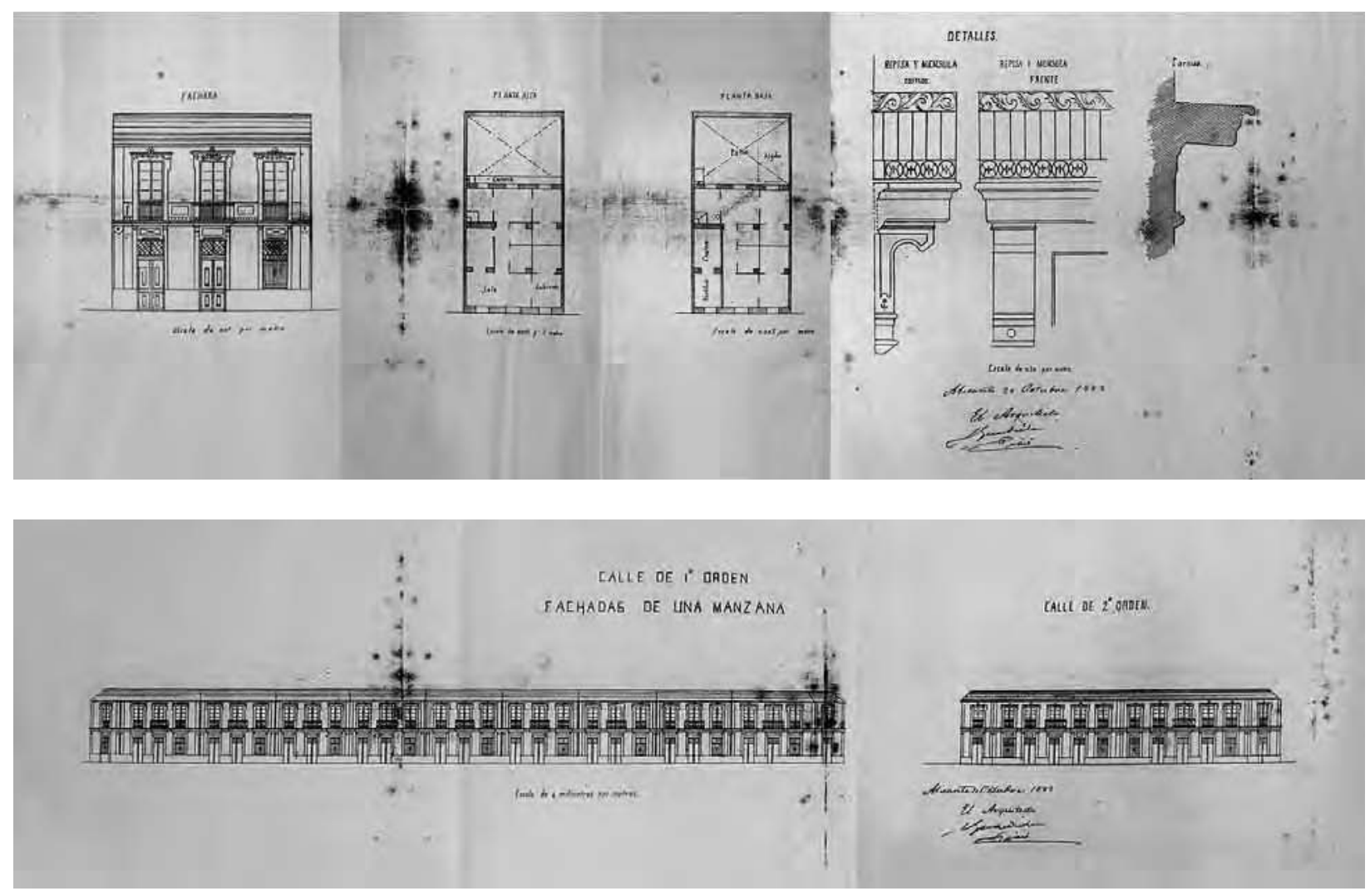

Fuente: Elaboración propia. 
FIGURA 3. EVOLUCIÓN DE LA TIPOLOGÍA RESIDENCIAL EN BENALÚA (1883-1900 / 1900-1920).

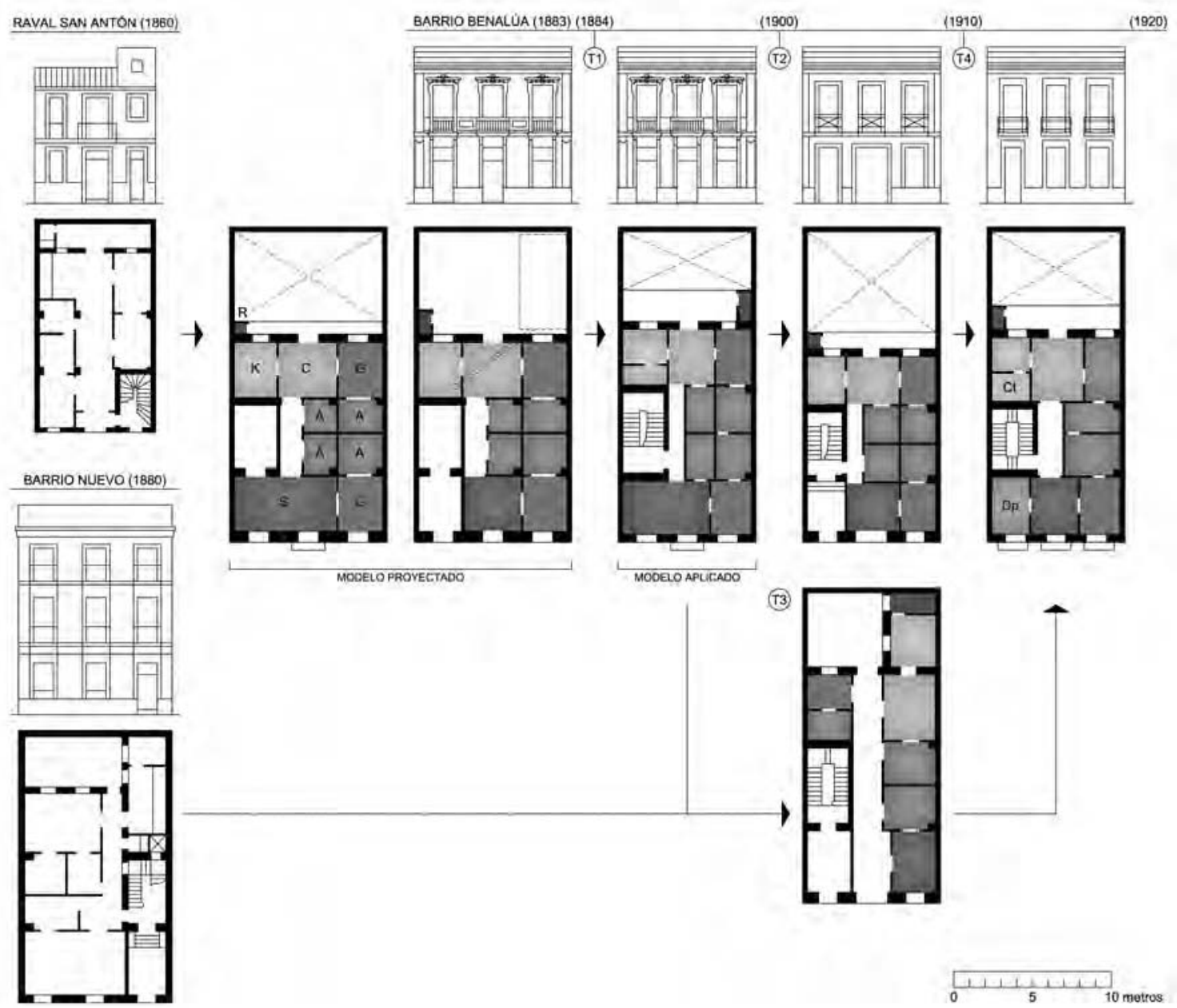

Fuente: Elaboración propia. 
m., resultando una superficie cuatro veces mayor que la mínima exigida por la normativa de la época. De este modo, la vivienda entre medianeras se concibió realmente con dos fachadas, una exterior a la calle y otra interior al generoso patio, separadas por un fondo edificable que garantizaba la iluminación y ventilación cruzada de todo el alojamiento. Aunque, al modo de proceder de la época, todavía algunas estancias (alcobas) se dispusieron interiores.

También constituyeron aspectos destacables del proyecto: la previsión de aljibes para la recogida de aguas pluviales, la agrupación de zonas húmedas en la vivienda, cierta adecuación de las circulaciones a la compatibilidad de los usos desarrollados en las diferentes estancias o el perfecto ajuste de la distribución del programa al entramado estructural.

En cuanto a la imagen de las casas, si bien ésta respondió a la composición derivada del racionalismo neoclásico, también reflejó un eclecticismo de avanzada personalidad. A diferencia de otros proyectos del momento, incluyó un conjunto de detalles muy elaborado, respondiendo a la voluntad moderna por diferenciar la obra del resto de las existentes en la ciudad, sin dejar que sus elementos imitaran otros al modo tradicional.

\section{El modelo aplicado (1884-1900)}

Las obras del barrio se iniciaron en 1884, catorce años antes del comienzo de la ejecución del ensanche de la ciudad (1898). Benalúa anticipó, por tanto, el crecimiento de Alicante, formando parte del conjunto de actuaciones determinantes de su evolución. La propuesta de un sistema de financiación basado en la unión de esfuerzos y voluntades ofertando facilidades para adquirir una vivienda en propiedad, cuando lo habitual era habitarlas en régimen de alquiler, atrajo a numerosas familias de clase media, tanto residentes en Alicante como en otros pueblos, haciendo posible la operación.

El mismo año (1884) se creaba en Gran Bretaña una Comisión Real para la vivienda de las clases trabajadoras que, un año después, proponía un proyecto de ley. Siguiendo la iniciativa, también crearon sus comisiones otros países como Alemania (1885) o Bélgica (1887) ${ }^{25}$. Sin embargo, la Comisión española, que se había anticipado junto con la francesa (1883), sin recibir el apoyo del Estado, aun habiendo concluido su trabajo, no comenzó a publicar resultados hasta $1889^{26}$, etapa en que los vecinos países europeos, como Bélgica (1889), Gran Bretaña (1890), Austria (1892) Francia (1894), fueron aprobando las que hoy pueden considerarse

Arias, op. cit., p. 48

Calle, 1984, p. 16. 
las primeras Leyes de "Casas Baratas"27. Los Congresos Internacionales de "Casas Baratas" (18891913), sirvieron para respaldar las posturas de los países anfitriones, en principio contrarias a la acción directa del Estado, avanzando después hacia modelos más intervencionistas ${ }^{28}$.

En España, hasta prácticamente finalizar el siglo XIX, las normativas de ensanche ocuparon mucha atención. En 1890 supuso un gran avance la creación de la Comisión de Reformas Sociales, viniendo a reorganizar la existente, hasta el momento sólo de carácter informativo, aumentando sus competencias para poder preparar proyectos de ley ${ }^{29}$. La Ley para el "Saneamiento, Reforma y Ensanche interior de las Poblaciones" 30 fue aprobada en 1895, desarrollándose a partir de entonces, como complemento, una amplia serie de disposiciones, entre ellas la legislación sobre "Casas Baratas", aunque tendrían que transcurrir tres lustros para su aprobación ${ }^{31}$.

El periodo en que actuó la SLDA (1884-1896) siguió, en consecuencia, caracterizándose por la ausencia de disposiciones legales al respecto. De hecho, la coyuntura de considerar a Benalúa como propiedad particular permitió gestionar sus obras con total libertad. De este modo, durante la construcción se introdujeron modificaciones sustanciales en el proyecto. La más importante consistió en reducir la superficie de los solares para disminuir la repercusión del suelo sobre las viviendas, construyéndose las casas con frente de $8,75 \mathrm{~m}$. en vez de $10 \mathrm{~m}$. La reducción de fachada se compensó con la ocupación de un mayor fondo en la parcela. Disminuyó ligeramente el patio abierto, ampliándose además el vuelo de las galerías. No se modificó el programa inicial, a excepción de incorporar en algunos casos un cuarto de despensa en las cocinas. Otras variaciones menores se orientaron en modificar las circulaciones cambiando las entradas de las diferentes estancias o a desagrupar las zonas húmedas de la vivienda (figura 3, T1).

En cualquier caso, transcurrido sólo un año desde el inicio de las obras, en 1885, el barrio llegó a convertirse en referente nacional. Desde Madrid, la SCA se refería a Benalúa en los siguientes términos: "El Ayuntamiento de Alicante ha encomendado la construcción de un barrio para obreros... que honrará á las autoridades que la han proyectado y servirá de estímulo y ejemplo á las de otras capitales y pueblos de importancia." Sin embargo, entre líneas se intuía

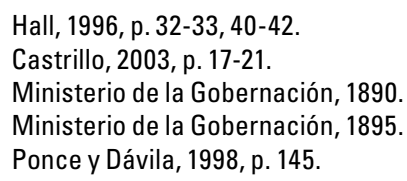


que la SLDA no estaba obteniendo resultados económicos ventajosos ${ }^{32}$.

Cuando en 1896 el Ayuntamiento de Alicante pasó a hacerse cargo de las obras del barrio, la SLDA había edificado 170 casas y emprendido la construcción de otras 8 , lo que supuso alcanzar el $80 \%$ de su propósito fijado inicialmente en 208 casas (13 manzanas de 16 casas $^{33}$. Los problemas que propiciaron el abandono fueron exclusivamente económicos. El proyecto se emprendió con los dividendos mensuales de 200 acciones (200 casas), suponiendo un ingreso muy inferior al necesario para ejecutar las obras al ritmo pretendido, ya que al coste de la edificación debía sumarse el de la urbanización. Se confiaba en recibir los beneficios económicos que otorgaba la Ley de Ensanche, cuya ejecución se demoró en Alicante. No obstante, la SLDA había realizado una inversión ambiciosa en la adquisición de terrenos y su venta, tras revalorizarse, sirvió para sanear temporalmente la empresa. Empero, los importes del ensanche (urbanización) nunca llegaron a hacerse efectivos, quebrando cualquier posibilidad de finalizar con éxito el proyecto emprendido.

Recuperar la confianza en el barrio, depreciado, requeriría el paso de algún tiempo. Por ello, debe

32 Sociedad Central de Arquitectos, 1885, p. 152.

33 Para financiar las obras se emitieron 200 acciones. Cada acción equivalía a una casa, por lo que debían construirse 200 casas. Las 8 casas adicionales servirían para pagar los honorarios facultativos del encargado de las obras, Pascual Pardo Jimeno, quien además fue el iniciador de la idea de construir Benalúa. entenderse ampliado su periodo de formación y considerar que alcanzó su consolidación, como modelo suburbano independiente, en los años que inauguraron el comienzo del siglo XX, al tiempo que volvía a retomarse en el país el debate sobre la construcción de barrios obreros ${ }^{34}$. Soria fundaba en 1894 la Compañía Madrileña de Urbanización para la creación de "barriadas cómodas, higiénicas y baratas" 35 , en la que también participaba Belmás, escogiendo un modelo de financiación semejante al empleado en Benalúa. La Ciudad Lineal se constituía en precursora de un modelo alternativo de ciudad extrarradio (campo-ciudad), como también lo había sido, aunque no en su forma, el barrio de Benalúa, coincidiendo en los mismos valores de cohesión social, utilidad, sencillez y economía, e incidiendo además en la importancia del desarrollo de infraestructuras y comunicaciones ${ }^{36}$.

\section{Primeras transformaciones (1900-1920)}

La conversión de la Comisión de Reformas Sociales en el Instituto de Reformas Sociales ${ }^{37}$ supuso la institucionalización de la política social del Estado

\footnotetext{
34 Repullés, 1891, p. 65-67.

35 Extraído del texto de presentación de la Revista La Ciudad Lineal en su primera época 1987-1901. Órgano Oficial de la Compañía Madrileña de Urbanización.

36 Terán, 1982, p. 73-83.

37 Presidencia del Consejo de Ministros, 1903.
} 
español ${ }^{38}$. Su reglamento de 1903 asentó las bases para el desarrollo de la legislación sobre "Casas Baratas" 39 . Para entonces, el debate sobre la intervención de los poderes públicos había avanzado considerablemente, incluso habían llegado a perder vigencia leyes como la francesa, reconociendo comoinsuficiente la iniciativa privada ${ }^{40}$. Con este conocimiento se redactó la legislación española, teniendo en cuenta los Congresos Internacionales de "Casas Baratas" y las legislaciones aprobadas en Gran Bretaña, Bélgica, Francia, Italia y Austria ${ }^{41}$.

En 1907, el Instituto de Reformas Sociales publicó la preparación de las bases para un proyecto de Ley y en 1910, su segunda edición aumentada ${ }^{42}$, traduciéndose estos documentos, en 1911, en la primera Ley de "Casas Baratas"43. Por su parte, la SCA también redactó, en 1908, un informe sobre la construcción de "Casas Baratas o Higiénicas" El Reglamento de aplicación de la Ley ${ }^{45}$, redactado en 1912, constaba de nueve capítulos, destinando el segundo a describir las condiciones técnicas que debían cumplir las viviendas, superando con creces las exigidas en las ordenanzas municipales. Este desequilibrio trató de ajustarse mediante

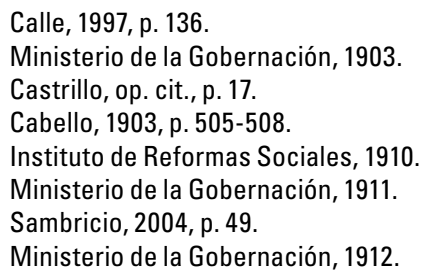

políticas sanitarias, exigiendo a los ayuntamientos que redactaran reglamentos de higiene ${ }^{46}$. El "Reglamento para la Higiene y Salubridad de la Ciudad de Alicante" ${ }^{47}$ fue aprobado en 1913. A partir de entonces comenzaron a publicarse numerosos estudios y propuestas sobre modelos de vivienda mínima, algunos editados previamente en otros países europeos ${ }^{48}$.

No obstante, para las construcciones que no se acogieran voluntariamente al régimen de "Casas Baratas", como fue el caso de Benalúa y la mayoría de las cooperativas en que confiaba el Estado, este marco normativo ampliamente desarrollado no se impuso de obligada aplicación, pudiendo los edificios seguir construyéndose, en caso de resultar rentable, del modo y con las carencias higiénicas que todavía se arrastraban del periodo decimonónico. De hecho, únicamente fueron construidas 1.295 casas al amparo de la ley ${ }^{49}$. La necesidad de modificar esta situación y de extender su aplicación a cualquier régimen de edificación de viviendas no comenzó a hacerse evidente hasta la trágica epidemia de gripe acontecida en 1918 y 1919. Por tanto, durante las dos primeras décadas del siglo 
$\mathrm{XX}$, los tipos arquitectónicos siguieron dependiendo de los intereses de propietarios y constructores.

En Benalúa, los criterios empleados por la SLDA no siguieron aplicándose. En el caso de mantener el programa (figura 3, T2), se adecuó al nuevo solar la proporción original, reduciendo también el fondo edificado. En el resto de los casos se establecieron ciertas pautas en la línea de los tipos previamente empleados por la burguesía, concretamente en el Barrio Nuevo (1880): construcción parcial de la cuarta crujía, prolongación del corredor hasta el patio, disposición de un cuarto de servicio vinculado a la cocina o formación de recibidores de entrada a las viviendas. Por lo general (figura 3, T3), se aumentó el fondo construido disminuyendo el número de estancias. Se llegó a disponer las cocinas ocupando parte de los patios y permitiendo el paso entre éstas y los retretes. Progresivamente, la carencia de espacio conllevó la desaparición de los gabinetes como elementos de transición entre salas y alcobas. Algunas de estas dependencias se transformaron en salas, perdiendo su relativa privacidad, y en el transcurso de la segunda década del siglo llegaron a funcionar directamente como alcobas, por primera vez iluminadas a través de los patios. Paralelamente, como evolución del gabinete, surgió la estancia designada como despacho con total libertad para desvincularse de la alcoba (figura 3, T4).

Los alzados también sufrieron importantes modificaciones. Comenzaron a incorporarse balcones volados en todos los huecos, perdiendo su significación la franja central como eje de simetría, optando en muchos casos por invertir las funciones de los vanos (transformar puertas en ventanas o ventanas en puertas), siendo habitual compartir el vestíbulo de acceso para eliminar las entradas a las plantas bajas cuando no funcionaban como cocheras o comercios. En la primera década del siglo, sobre la base decimonónica de estructura racionalista, los recercados, pilastras e impostas fueron perdiendo su particular diseño hasta quedar todos iguales, con la misma forma y entidad. La ausencia total de ornamento, sin definirse guardapolvos u otros detalles, supuso el abandono del lenguaje ecléctico de cierta modernidad que caracterizó el diseño original del barrio, retrocediendo a la imagen de las viviendas construidas en la segunda mitad del siglo XIX. Con el comienzo de la segunda década, la desornamentación se orientó en otro propósito, abandonar la estructura neoclásica racionalista y los elementos que la identificaban, eliminando las molduras o pilastras que señalaban los elementos constructivos $^{50}$.

50 García, 1980. 


\section{FIGURA 4. EVOLUCIÓN DE LA TIPOLOGÍA RESIDENCIAL EN BENALÚA (1920-1931).}

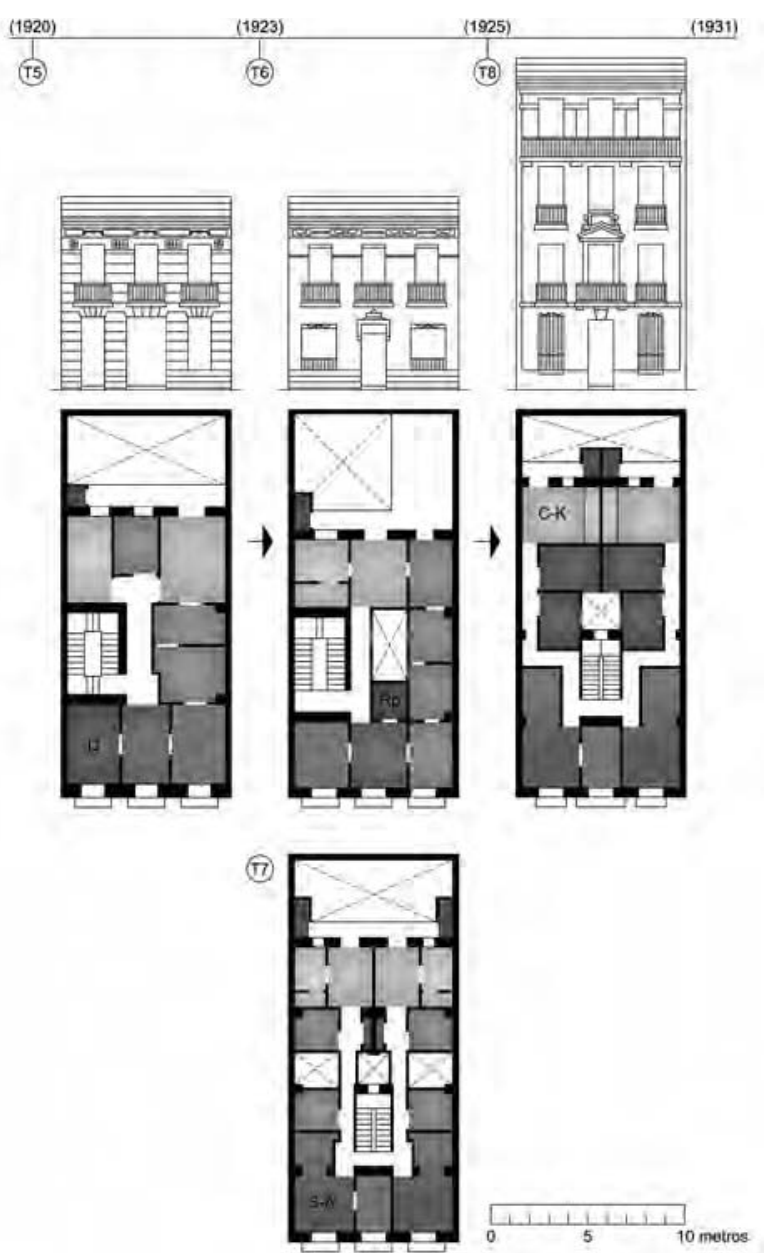

\section{Variaciones sobre la herencia decimonónica (1920-1931)}

En los primeros años veinte, los programas y distribución de las viviendas no aportaron variaciones relevantes, salvo por comenzar a permitir la disposición de alcobas con fachada a la vía pública y a sustituir puntualmente esta primera designación por la de dormitorio. Se sostuvo el tipo tradicional, asumiendo el hecho de poder modificar la ubicación y relación entre las diferentes estancias. El factor que exige diferenciar las casas construidas a partir de 1920 se refiere a la terminación de los alzados (figura 4, T5). Sobre las fachadas comenzaron a surgir nuevos tipos de decoración, repertorios regionalistas vinculados a la tradición popular: aleros de madera, estucos y serigrafiados, cerámicas incrustadas o cristaleras de colores. Dejó de existir, como en la ciudad decimonónica, una homogeneidad lingüística identificativa de la imagen urbana.

Mientras, el debate de la vivienda económica fue adquiriendo una mayor dimensión desde la óptica del urbanismo, primero como discurso teórico y, a partir de 1914, como respuesta a la necesidad de reconstruir las ciudades. La vivienda dejó de considerarse un problema aislado para integrarse en el modelo de ciudad, influyendo en su forma y

Fuente: Elaboración propia. 
determinando su crecimiento. Tanto el modelo de ensanche español como el debate sobre la conveniencia de los barrios obreros quedaron obsoletos frente a los oportunos planteamientos europeos sobre ciudades jardines o satélites, sin obtener la Ciudad Lineal su merecido reconocimiento ${ }^{51}$.

En este contexto, el Congreso sobre Habitación y Urbanización celebrado en Londres en 1920, al que asistieron arquitectos del Instituto de Reformas Sociales, organismo que ese mismo año sería absorbido por el Ministerio de Trabajo ${ }^{52}$, marcó las políticas a emprender tanto en la construcción de viviendas como en los trazados urbanos, insistiendo además en el reparto de responsabilidades. Por primera vez se fijaron las dimensiones y el programa de la vivienda mínima ${ }^{53}$, parámetros que sin duda influyeron en la redacción de la segunda Ley española, de 1921, de "Casas Baratas"54. Su Reglamento de aplicación, redactado en 1922, constaba de quince capítulos, destinando parte del primero a fijar las condiciones mínimas exigibles en las viviendas: de los terrenos, de las casas familiares (relativas a la estructura y a la higiene), de las casas colectivas, de los grupos de casas y ciudades satélites, y prescripciones generales ${ }^{55}$. Sin embargo, debían ser de nuevo los propietarios, por voluntad

51 Sambricio, op. cit., p. 31-32.

52 Presidencia del Consejo de Ministros, 1920.

53 Sambricio, op. cit., p. 156-158.

54 Ministerio de Trabajo, 1921.

55 Ministerio de Trabajo, Comercio e Industria, 1922. propia, los que se adscribieran a los beneficios de la ley. De nada sirvió que las cooperativas de obreros se implicaran en esta ocasión porque no obtuvieron el crédito necesario, incumpliendo los poderes públicos su propia normativa ${ }^{56}$.

Empero, un cambio sustancial se produjo en 1923. Se aprobaron las "Instrucciones técnico-sanitarias para pequeños municipios" $" 57$, un documento valiosísimo que puso de manifiesto las penosas condiciones en que se encontraba el país, así como las "Condiciones higiénicas de las viviendas y prescripciones técnico-sanitarias para el Ensanche y Reforma interior de las Poblaciones" ${ }^{58}$, aplicables por primera vez en el sector de la construcción libre de viviendas, aunque sin llegar a equiparar la legislación de "Casas Baratas". En el periodo de Dictadura amparada por la Monarquía que comenzó en septiembre de 1923 se aprobó, en 1924, la tercera y última Ley de "Casas Baratas" 59 . El sistema funcionó con diferencia, logrando que fluyera el crédito hasta agotarse, obligando además a los ayuntamientos a construir. Sin embargo, no pudo evitarse la especulación, impidiendo a las clases más humildes acceder a la vivienda. En tanto, en 1925, fue aprobado el "Reglamento de Sanidad Municipal"60, exigiendo a los ayuntamientos

\footnotetext{
56 González, op. cit., p. 223.

57 Ministerio de la Gobernación, 1923a.

58 Ministerio de la Gobernación, 1923b.

59 Presidencia del Directorio Militar, 1924.

60 Presidencia del Directorio Militar, 1925.
} 
FIGURA 5. PLANO

GENERAL DE

ALICANTE,

APROXIMADAMENTE

DE 1925. COMPOSICIÓN

DE DOS HOJAS DE UN

TOTAL DE CUATRO.

Fuente: Ayuntamiento de Alicante.
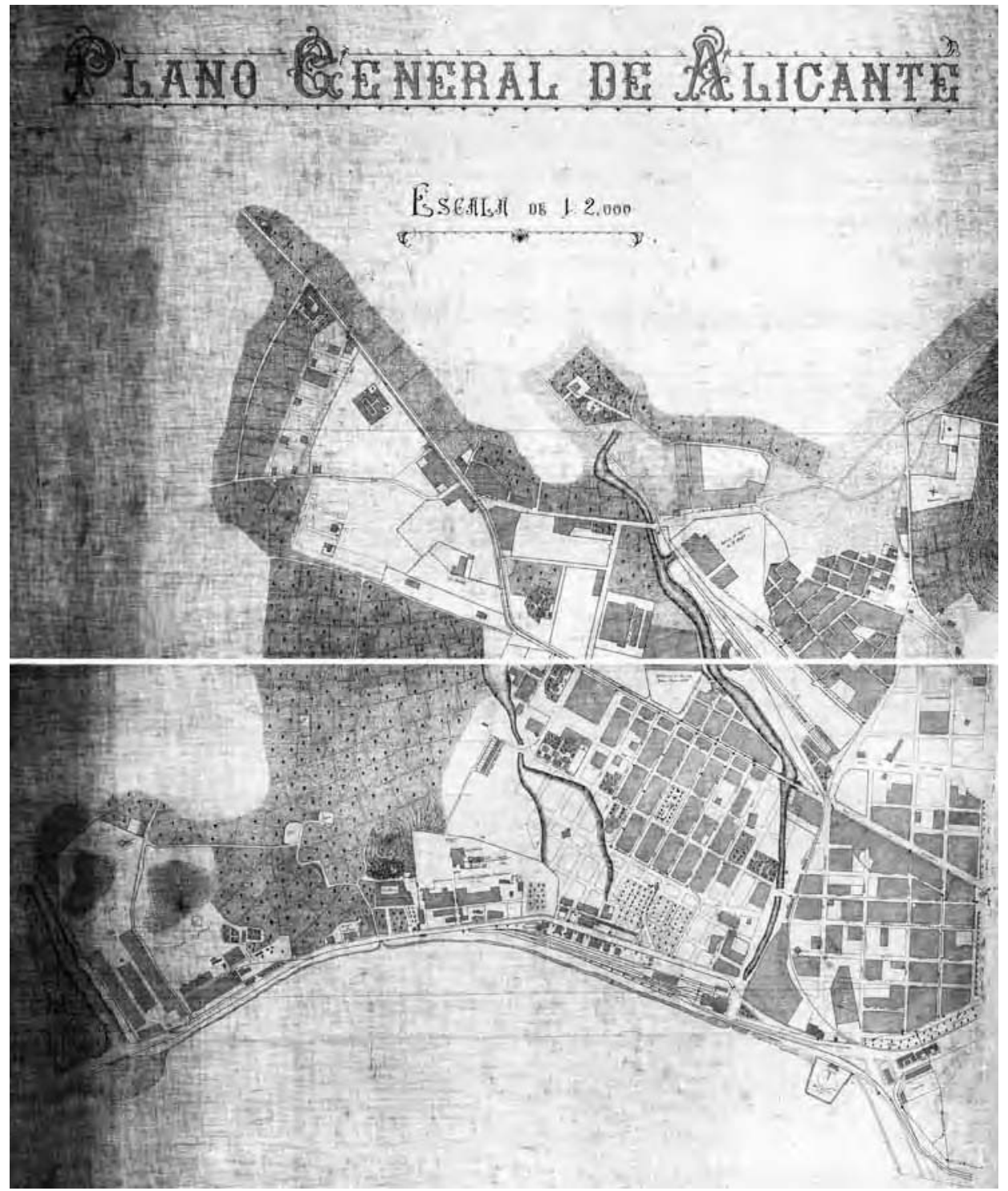
el cumplimiento de las instrucciones técnico-sanitarias aprobadas en 1923. Este reglamento describió, además, por primera vez en el sector de la construcción libre de viviendas, el número de estancias que debía integrar el alojamiento, aunque no mínimos de cubicación como establecía el Reglamento de "Casas Baratas". Incluso, se aprobaron normativas de "Casas Económicas"61 dirigidas exclusivamente a las clases medias, en 1925, y a los funcionarios del Estado, en 1927.

En consecuencia, el marco normativo municipal se vio ampliamente afectado por las determinaciones estatales, resultando de su aplicación una transformación sustancial de las tipologías residenciales empleadas. La exigencia, que en mayor medida determinó el cambio en los tipos arrastrados del periodo decimonónico, fue que ninguna estancia pudiera ubicarse al interior. De este modo, transcurridos treinta años, el modelo de vivienda de Benalúa perdió su validez, considerándose inadmisible que algunas estancias carecieran de ventilación directa. Comenzaron a construirse patios interiores (figura 4-T6) y, aprovechando los espacios residuales, pequeños cuartos roperos, aunque se siguieron admitiendo segundas luces. El mecanismo de designar piezas compuestas permitió justificar que las dependencias disponían de fachada, aunque en la práctica siguieran ventilando unas estancias a través de otras. Progresivamente, fueron las cocinas, reduciendo su superficie o integrándose en los comedores, y las salas, desapareciendo para fragmentarse en un mayor número de piezas, las que fueron perdiendo relevancia en el programa. Y, aunque de momento dejaron de construirse las crujías posteriores, algunas galerías terminaron extendiéndose para formar azoteas.

El segundo aspecto que influyó determinantemente en transformar el tipo tradicional vino de la decisión tomada por gran número de propietarios de construir, sobre la misma parcela, dos viviendas por planta, obteniendo un mayor aprovechamiento. La aparición de este nuevo tipo no significó el abandono de la primera disposición, por lo que convivieron indistintamente ambas tipologías, sin llegar a apreciarse diferencias en las fachadas. El alzado siguió manteniendo la composición clásica heredada, basada en la disposición simétrica de tres huecos sin reflejar que, interiormente, la planta se compartimentaba en dos viviendas (figura 4, T7).

Alcanzado el cuarto de siglo, los intereses particulares influyeron todavía más sobre el tipo residencial. Comenzaron a realizarse obras de naturaleza muy variada, ampliaciones o nuevas construcciones tanto de planta baja y piso, como de dos o tres pisos (figura 4, T8). Las fachadas también respondieron a gustos bien distintos. Los propietarios se encargaron de personalizar el aspecto de sus casas

61 González, op. cit., p. 224-225. 
y de determinar en consecuencia la imagen del barrio. Benalúa recuperó la riqueza ornamental que quedó en suspenso durante las primeras décadas del siglo, pero no de forma homogénea sino combinando los lenguajes clásico, historicista y regionalista.

\section{Primeros intentos de modernidad (1931-1939)}

La crisis económica de 1929 y el debate sobre la vivienda mínima, que se intensificó en el II CIAM celebrado en Frankfurt el mismo año, determinaron el contexto en que se instauró en España la Segunda República (1931-1936). El Patronato de Política Social Inmobiliaria del Estado ${ }^{62}$ fue creado en 1931, absorbiendo las competencias en política de vivienda. Para el Patronato, la legislación de "Casas Baratas" y el resto de normativas que habían coexistido debían revisarse, iniciándose en 1933 un proyecto de reforma ${ }^{63}$ que, salvo modificaciones puntuales, nunca llegó a concluirse. De hecho, el marco normativo de "Casas Baratas" no fue derogado hasta 1939.

Coincidiendo con el nacimiento de los Colegios Oficiales de Arquitectos, en 1931, el periodo se inició con nuevas aportaciones: construcción de áticos, variadas disposiciones de huecos en fachada, llegando a reflejar en su caso las dos viviendas que componían la planta o a sustituir los balcones tradicionales por ventanas. Si la distribución del modelo de Benalúa perdió su validez en la década de los veinte, diez años después también la imagen de las casas perdió su homogeneidad, no sólo en su ornamento sino por romper el ritmo compositivo que la caracterizó durante cuatro décadas.

A las primeras actuaciones que introdujeron estos cambios (figura 6, T9 y figura 6, T10), muy pronto se sumó una nueva arquitectura adecuada a los tiempos modernos ${ }^{64}$. En la primera mitad de la década, con clara vocación mediterránea, aparecieron los primeros ejemplos que simplificaron las formas y ornamentos, asumiendo el protagonismo la geometría sencilla, el contraste de materiales o el color (figura 6, T11). Pero fue a partir de 1935, cuando amparados en el marco social legal, comenzaron a construirse los primeros ejemplos de residencia obrera. Para las construcciones que empezaron en 1935 y finalizaron en 1936, la Ley de "Previsión contra el Paro" ${ }^{65}$ concedió los mismos beneficios que en su momento otorgó la Ley de "Saneamiento, Reforma y Ensanche interior de las Poblaciones" de 1895: exención del arbitrio municipal para las casas de renta cuyos alquileres no superaran un máximo mensual. Al amparo

64 Martínez, 1998.

65 Ministerio de Trabajo, Sanidad y Previsión, 1935 
FIGURA 6. EVOLUCIÓN DE LA TIPOLOGÍA RESIDENCIAL EN BENALÚA (1931-1939).

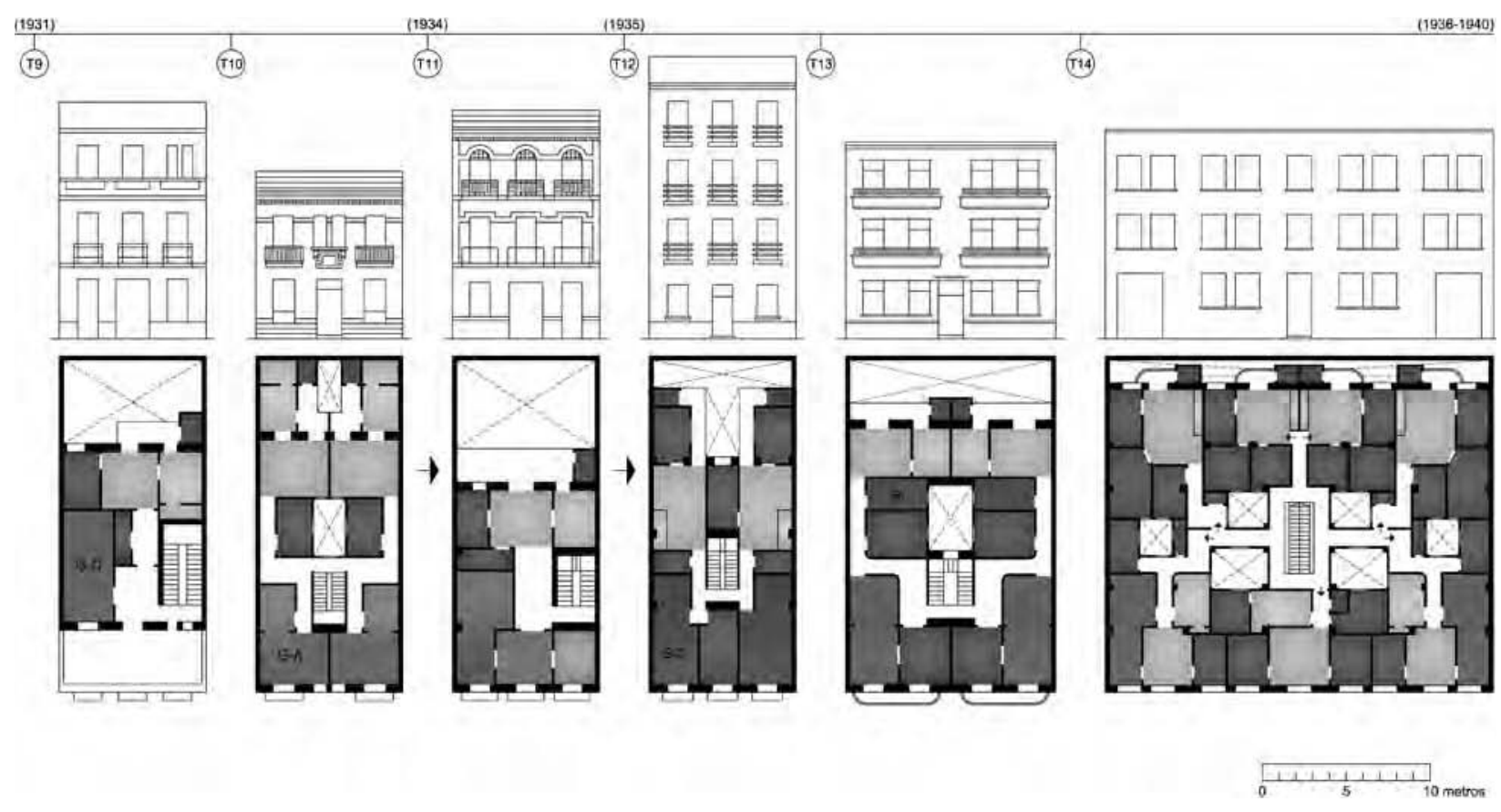

Fuente: Elaboración propia. 
de esta ley, conviviendo con las propuestas que sólo incorporaron signos aislados del nuevo lenguaje moderno (figura 6, T12), se levantaron los primeros ensayos racionalistas, enfatizando la desornamentación del plano, la geometría escueta, la horizontalidad o el dinamismo. Se distinguieron de cualquier actuación precedente (figura 6, T13), llegando a soluciones de extrema austeridad y estandarización para contener incluso una veintena de viviendas (figura 6, T14).

Las distribuciones, aunque concebidas racionalmente en base a cierta zonificación de espacios, todavía reflejaban la forma heredada, resultando obvias las servidumbres de paso y segundas luces. No obstante, apareció ocasionalmente una pieza de baño independiente del retrete en el interior del alojamiento, solución que sólo se había incorporado en residencias de alto estatus. Se proyectaron puntualmente los retretes integrados junto al resto de estancias en los edificios que contenían un mayor número de viviendas, al no disponer todas de patios o galerías. Eso sí, la incorporación de los cuartos de aseo en los alojamientos de clase media no fue habitual hasta alcanzar los años cuarenta. Por otro lado, volvió a producirse en esta década la ocupación de los patios, no sólo con dependencias de cocina sino también con estancias de dormitorio.

La Guerra Civil (1936-1939) supuso un paréntesis en la construcción. Si bien en la ciudad pueden documentarse algunas actuaciones en los primeros años de contienda, en lo que al barrio se refiere, una vez finaliza los proyectos emprendidos, no se dispone de documentación que acredite la ejecución de obras. Comenzó a gestarse, no obstante, la etapa de las instituciones franquistas, sustituyendo entre otros organismos el Patronato de la República, comenzando a funcionar en su lugar, en 1938, la Junta Administradora Nacional de "Casas Baratas y Económicas"66.

\section{Tradición, racionalismo y primeros ejemplos "desarrollistas" (1939-1956)}

\section{ETAPA INMEDIATA DE POSGUERRA (1939-1944)}

Finalizada la Guerra Civil, en 1939, el Estado basó su política en potenciar la agricultura como base de la autarquía económica, volcándose en la construcción de núcleos rurales como focos industriales. La reconstrucción se centralizó en una serie de organismos: la Dirección General de Arquitectura, para la ordenación nacional de la arquitectura y sus actividades profesionales; la Dirección General de Regiones Devastadas, para abordar la reconstrucción de localidades destruidas por los bombardeos; y el Instituto Nacional de Colonización, para

66 Ministerio de Organización y Acción Sindical, 1938. 
FIGURA 7. EVOLUCIÓN DE LA TIPOLOGÍA RESIDENCIAL EN BENALÚA (1939-1944).

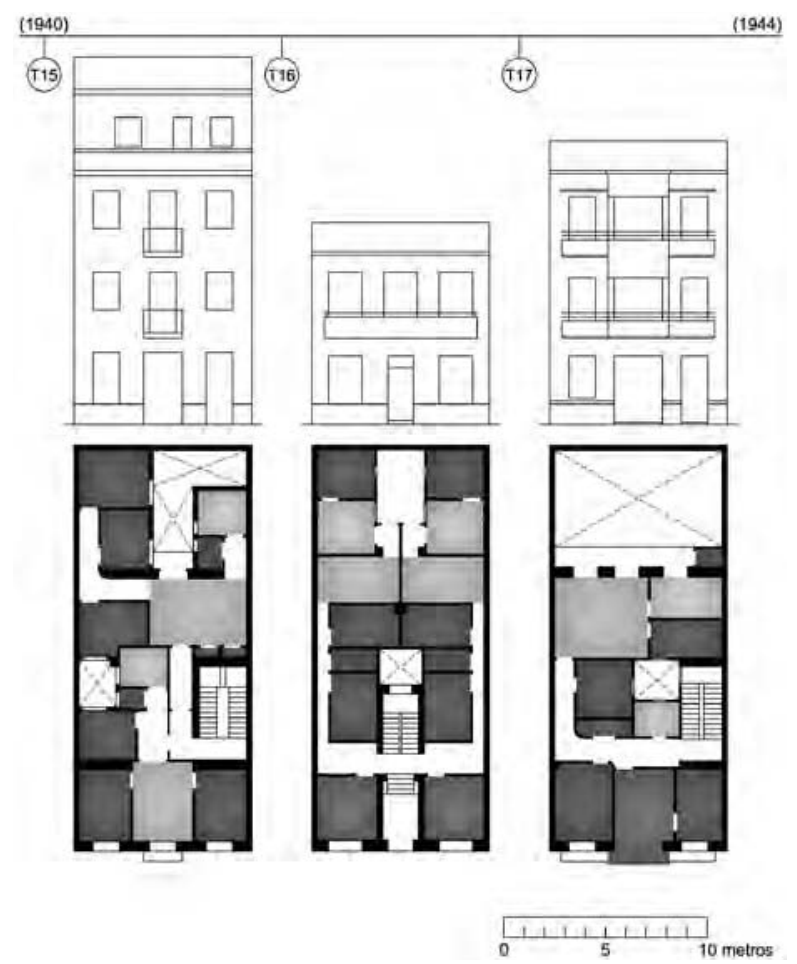

Fuente: Elaboración propia.

ARTíCUL 0: Primeras políticas de vivienda en España y su influencia en la evolución de la tipología residencial: el caso de Benalúa (1883-1956) / Raquel Pérez del Hoyo y María Elia Gutiérrez Mozo
FIGURA 8. EVOLUCIÓN DE LA TIPOLOGÍA

RESIDENCIAL EN BENALÚA (1944-1950).

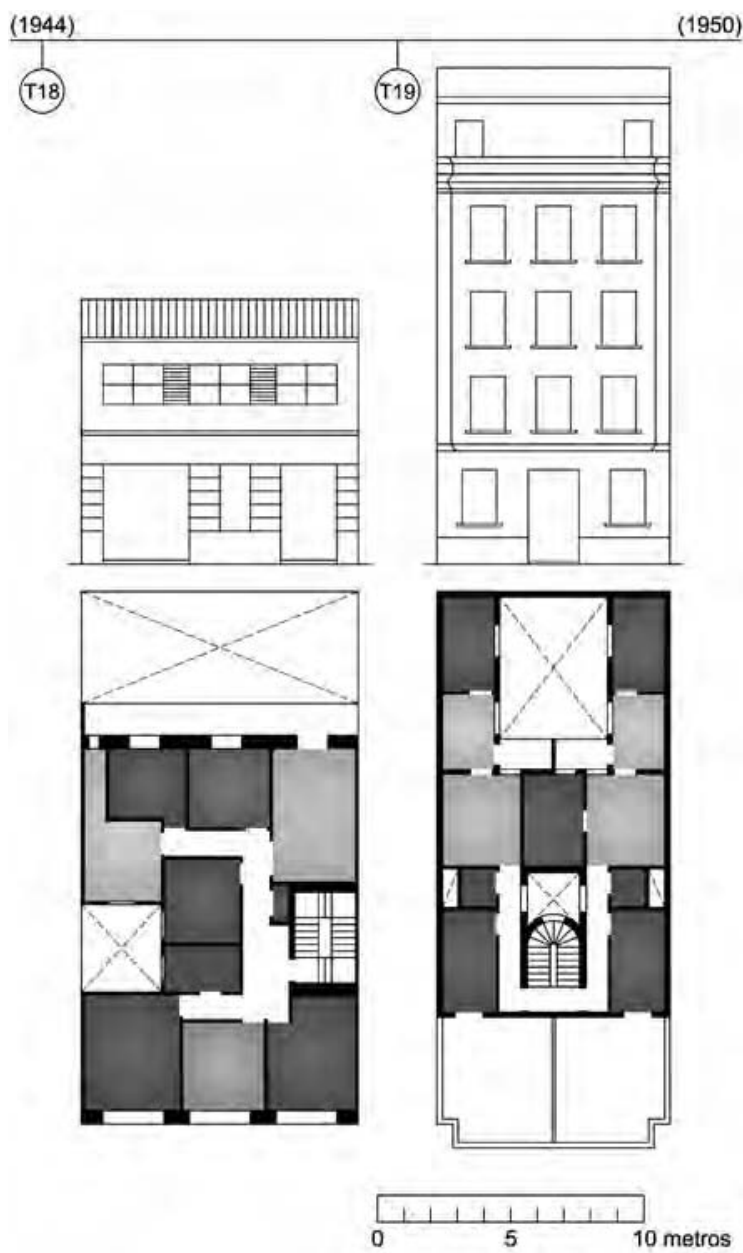

Fuente: Elaboración propia.

revista invi ํำ 78 / Agosto 2013 / Volumen N² 28: 221-255 243 
la creación de nuevos poblados agrícolas. En materia de vivienda fue creado el Instituto Nacional de la Vivienda ${ }^{67}$, derogando la legislación anterior. Se iniciaba en el país el sistema de viviendas protegidas, una planificación que se iría concretando en los sucesivos Planes Nacionales de Vivienda. El primer plan (preparatorio) fue aprobado en 1943, recogiendo la experiencia heredada de la Leyes de "Casas Baratas" y la incipiente política de vivienda rural $^{68}$. El Instituto Nacional de la Vivienda publicó entonces las nuevas ordenanzas que debían regular, con carácter nacional, la construcción de "Viviendas de Protección Oficial", influyendo de forma determinante en el ejercicio de la profesión. Comenzó a gestarse un Plan de Reconstrucción Nacional en el que también se involucraron los profesionales del sector, como se manifestó en la Segunda Asamblea Nacional de Arquitectos celebrada en Madrid, en 194069.

En esta etapa inmediata de posguerra sólo se desarrollaron actuaciones de reconstrucción y ampliación en base a los tipos más modestos establecidos en los últimos años de la República. En general, se mantuvo la estructura de tres huecos en fachada desapareciendo cualquier referencia historicista, conviviendo los planteamientos más tradicionales (figura 7, T15), las propuestas sin terminar de

\footnotetext{
67 Jefatura del Estado, 1939. Ministerio de Trabajo, 1939.

Candau, 2005, p. 271.

69 Terán, op. cit., p. 137, 141-142.
}

romper con el pasado (figura 7, T16) y, con mayor relevancia, los singulares diseños basados en la gramática moderna (figura 7, T17). También, comenzaron a incorporarse los característicos miradores, en principio prismáticos, avanzando después hacia formas más dinámicas.

La preocupación higienista se tradujo en el abandono progresivo del empleo de segundas luces. No obstante, los comedores se mantuvieron como paso obligado a otras estancias; aunque los retretes se integraron en el interior de los alojamientos, no se proyectaron siempre completos como aseos o baños; y en la ocupación parcial de la cuarta crujía, en la mayoría de los casos, como si de una solución tipo establecida se tratara, se situaron primero las cocinas accediéndose después a un dormitorio, justificando su ubicación por vincularlo al servicio.

\section{Avances en la política de vivienda (1944-1950)}

A partir de 1944, el marco normativo estatal volvió a cambiar sustancialmente. Obtener una Cédula de Habitabilidad fue requisito indispensable ${ }^{70}$. Las nuevas condiciones higiénicas que debían reunir las viviendas, protegidas o no, establecieron

70 Ministerio de la Gobernación, 1943. 
la primera regulación de parámetros aplicables al sector libre de la construcción ${ }^{71}$. Las analogías que pueden establecerse con las actuales Normas Urbanísticas de Alicante (Plan General, 1987), constatan la relevancia de este cambio normativo. Paralelamente, en 1946, la Ley de "Arrendamientos Urbanos"72 culminó las políticas arrastradas desde mediados del siglo XIX, a la vez que los Planes de Vivienda Protegida ${ }^{73}$ impulsaron cuantiosamente la construcción de alojamientos de clase media. De hecho, prácticamente la totalidad de las obras ejecutadas en Benalúa se acogieron a los beneficios que otorgaba la calificación de "Viviendas Bonificables".

Muchas actuaciones en estos años, tanto en distribución como en imagen, dieron un gran paso hacia las formas y concepción modernas. Proyectar todas las estancias independientes supuso prescindir de los tipos heredados y avanzar en la línea de un modelo completamente nuevo (figura 8, T18). Si bien otras intervenciones optaron por aferrarse a los tipos establecidos, también tuvieron (por ley) que incorporar mejoras, por ejemplo: piezas de aseo o baño completas.

Los alzados, aunque simétricos, comenzaron a romper la imagen pesada del muro de carga tan arraigada en las composiciones tradicionales. El

71 Ministerio de la Gobernación, 1944.

72 Jefatura del Estado, 1947.

73 Jefatura del Estado, 1944 y 1948. Ministerio de Trabajo, 1945. lenguaje moderno planteaba sustituir los vanos recortados de forma aislada por bandas horizontales, rasgando el muro en toda su longitud. Si bien los cerramientos seguían funcionando como elementos de carga, combinar diferentes texturas de acabado permitía distinguir estas franjas con mayor protagonismo que el soporte estructural. Por otro lado, el mirador dejó de ser un elemento localizado en fachada, pasando a ocuparla totalmente para aumentar la superficie de las viviendas (figura 8, T19). Comenzaron, de este modo, a entreverse las primeras actuaciones encaminadas a convertir la construcción en un negocio verdaderamente rentable. Dependiendo de las limitaciones económicas, pudieron construirse casas contiguas con desproporciones en altura de hasta tres pisos.

\section{Hacia nuevas propuestas de regulación de suelo y ordenación urbana (1950-1956)}

El fracaso de la política agraria y el desplazamiento de la población a las ciudades inauguraron una nueva etapa. Los esfuerzos se reorientaron en la planificación del crecimiento urbano, exigiendo la formación de planes generales para evitar la especulación y poner en marcha un nuevo sistema 


\section{FIGURA 9. EVOLUCIÓN DE LA TIPOLOGÍA RESIDENCIAL EN BENALÚA (1950-1956).}
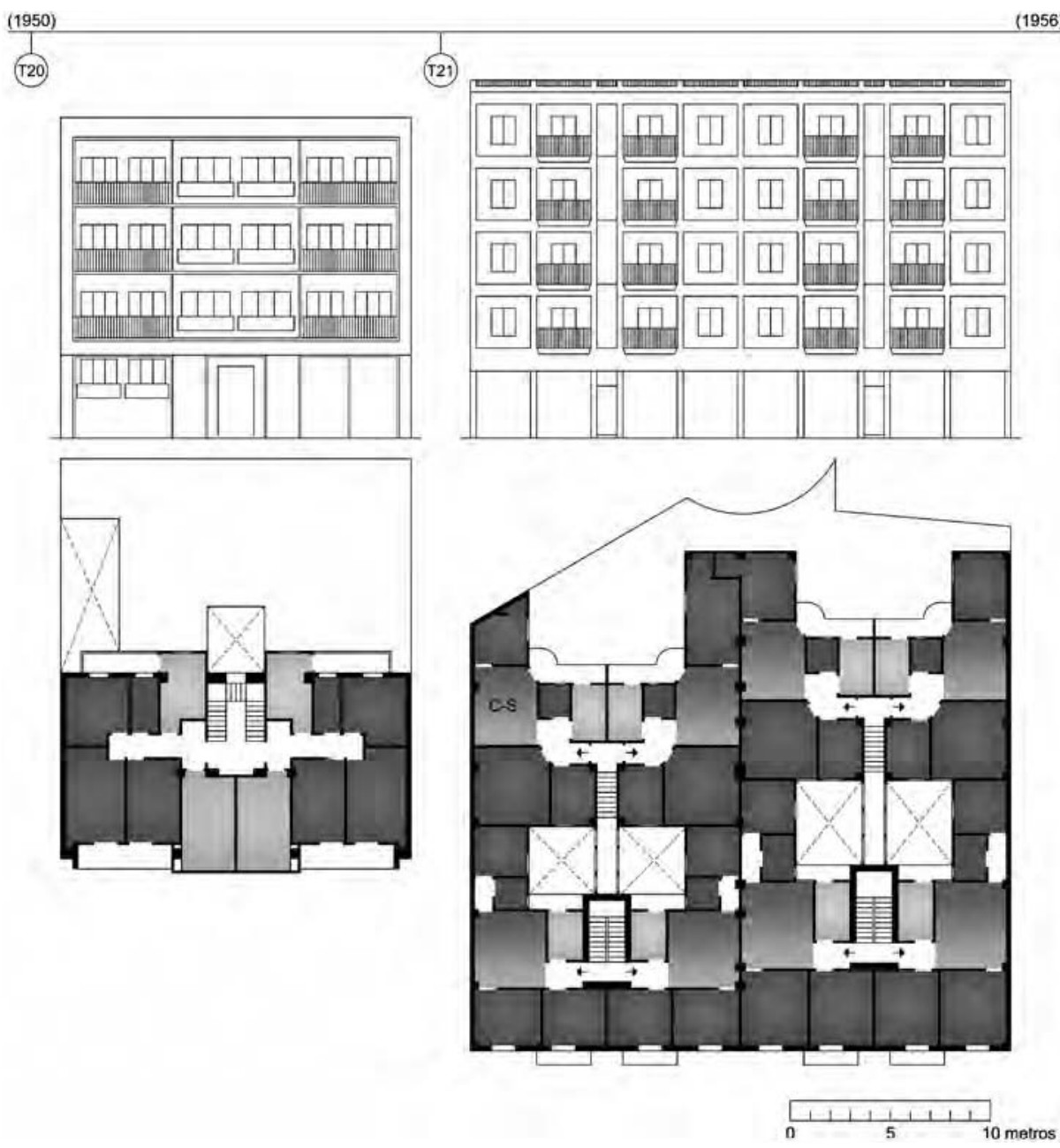

Fuente: Elaboración propia. 
FIGURA 10. PLAN GENERAL DE ORDENACIÓN URBANA DE ALICANTE (1956).

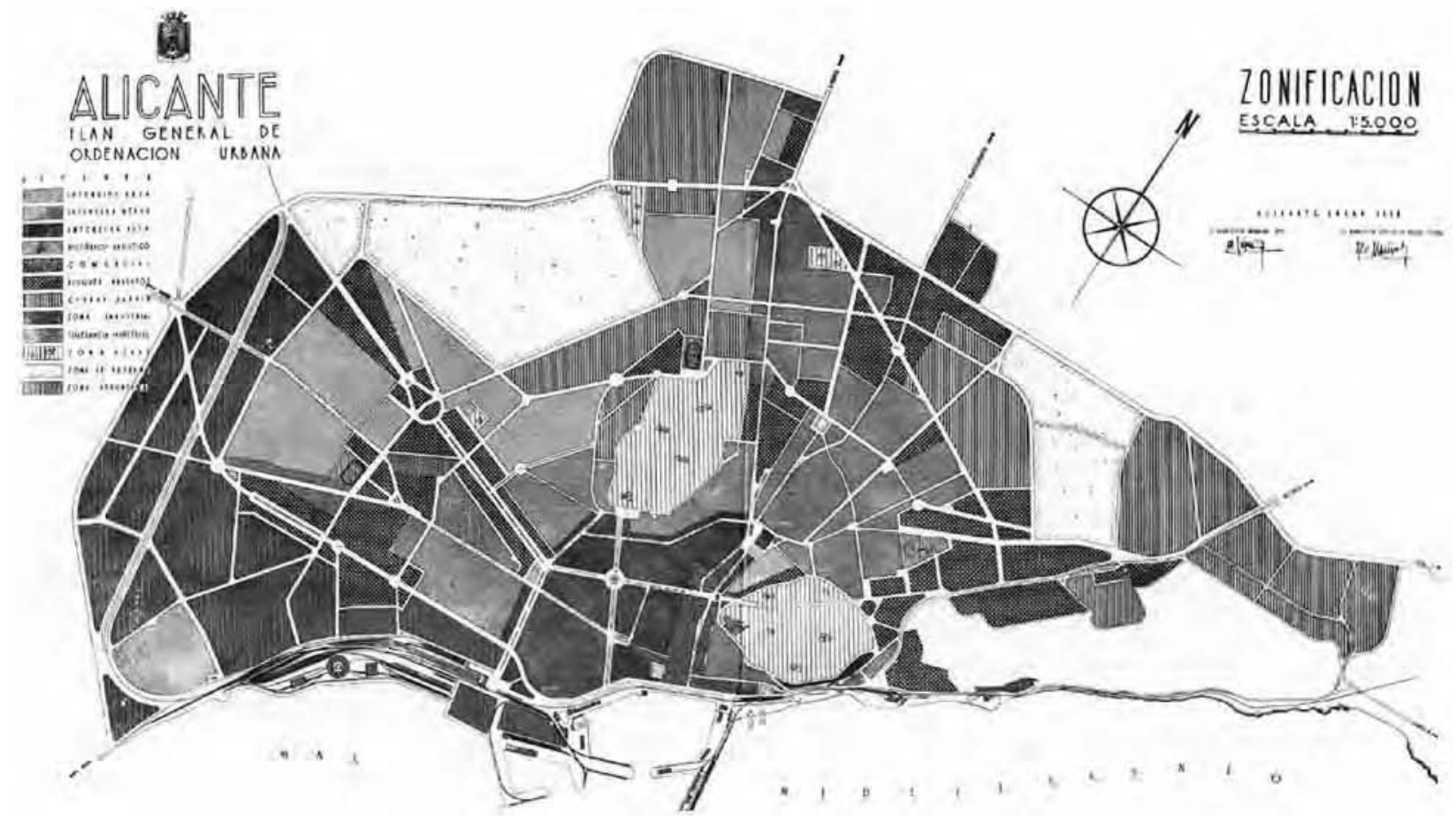

Fuente: Giménez, Giner y Varela, 1985, p. 43. 
de "Viviendas de Renta Limitada" 74 centrado en estimular la iniciativa privada ${ }^{75}$. Asentadas las bases, en 1955 se inició el primer Plan Nacional de Vivienda para llevar a cabo la construcción de 550.000 alojamientos. En 1956 debían emprenderse las obras de casi 100.000 viviendas en el país, de las cuales 128 correspondían a Alicante ${ }^{76}$.

Los edificios diseñados en esta etapa se reafirmaron como modernos y actuales (figura 9, T20). Las viviendas superaron cualquier herencia y las fachadas se mostraron en su máxima expresión racionalista, sin percibirse en la composición de jerarquías de otras épocas. No obstante, anticipándose al nuevo periodo que comenzaría con la aplicación del primer Plan General de Alicante (1956), aparecieron los primeros edificios (figura 9, T21) más preocupados por la optimización del negocio que en la concepción de las formas. Nada aportaron en la evolución tipológica del habitar del barrio, más bien recuperaron ciertas herencias cuestionables, planteando incluso viviendas interiores. Su relevancia radica en alcanzar tempranamente las mayores alturas que en breve legalizaría la nueva planificación.

74 Jefatura del Estado, 1954. Ministerio de Trabajo, 1955a.

75 Sambricio, 2000.

76 Ministerio de Trabajo, 1955b y 1955c.
No entraremos a valorar las directrices del Plan General, aunque puede resultar contradictorio que la ley que obligó a su redacción, sobre "Régimen del Suelo y Ordenación Urbana" de 1956, tuviera precisamente como objetivo evitar la especulación $^{77}$. La Ley del Suelo constituyó el marco jurídico del urbanismo nacional hasta su reforma en 1975 y reconoció al planeamiento como fundamento de la ordenación urbana ${ }^{78}$. El nuevo marco normativo condujo a la creación de un órgano superior, creándose en 1957 el Ministerio de la Vivienda ${ }^{79}$. En este ministerio quedaron integrados: el Instituto Nacional de la Vivienda, que pasó a constituir la Dirección General de la Vivienda; la Dirección General de Arquitectura y Urbanismo ${ }^{80}$, que comenzó a denominarse Dirección General de Urbanismo; la Dirección General de Regiones Devastadas; y otros servicios relacionados.

La aplicación de los Planes Generales, así como la Ley del Suelo y el funcionamiento del Ministerio de la Vivienda dieron paso a un nuevo periodo "desarrollista" cuyo estudio supondría sobrepasar los límites pretendidos. La exigencia de mayores densidades como paradigma de modernidad representa, por tanto, el estado último de nuestro recorrido. 


\section{Conclusiones}

El problema de la vivienda en España vino derivado de la especulación inmobiliaria, tanto en el interior de las ciudades como en los ensanches de las poblaciones. Las primeras intervenciones tendieron al arrendamiento, por ser el modo más rápido y económico, pero la libertad que se concedió a la burguesía permitió encubrir un negocio monopolizado con la consecuente subida de alquileres y descuido de la higiene. La vivienda no fue el centro de los esfuerzos administrativos sino un aspecto más de la política social que giraba en torno al trabajo. Si por ley se congelaban los alquileres, disminuía la construcción y se perdían puestos de trabajo, y si se reactivaba el sector, con la exención de impuestos y sin incomodar con exigencias higiénicas, volvían a subir los precios.

Este comportamiento cíclico sólo se percibió preocupante en los momentos de verdadero conflicto social: en los periodos de guerra y posguerra, con la paralización económica y, por tanto, de la construcción; y con los desplazamientos masivos de población a las ciudades en busca de trabajo en la industria. En España pueden identificarse, por un lado, las etapas inmediatas a la I Guerra Mundial (1914-1918) y Guerra Civil (1936-1939) y, por otro, los desplazamientos de población en el último tercio del siglo XIX y mediados del siglo XX, coincidiendo con el fracaso de la política agraria y las consecuencias de la II Guerra Mundial.

En este contexto, la evolución de la tipología residencial dependió casi siempre de la voluntad de los propietarios. En el siglo XIX, ante la inexistencia de un modelo normativo, únicamente desde las teorías higienistas, como fue el caso representativo de Benalúa, y puntualmente desde las políticas sanitarias, se lograron introducir mejoras de habitabilidad. La intervención del Estado comenzó tardíamente con la legislación de "Casas Baratas" (leyes de 1911, 1921 y 1924), pero este marco normativo ampliamente desarrollado en las primeras décadas del siglo XX no se impuso de obligada aplicación. El sector libre de la construcción siguió rigiéndose por las normativas municipales que mantenían las carencias del periodo decimonónico. Fue en 1923, cuando algunas determinaciones estatales, aunque sin equiparar las de "Casas Baratas", se aplicaron por primera vez a todas las viviendas, apreciándose los primeros cambios sustanciales en las tipologías heredadas, como fue la incorporación de patios interiores. La coyuntura del cambio también propició la aparición de nuevos tipos pensados para obtener mayores aprovechamientos. Por su parte, la Ley para fomentar el alquiler de 1935, aunque su objetivo principal fue prevenir el paro, conllevó asimismo la aparición de los primeros tipos de residencia obrera concebidos para contener un mayor número de viviendas. 
El sistema de "Viviendas de Protección Oficial" de 1939, no impuso nuevas exigencias al sector libre de la construcción. Los esfuerzos se volcaron en la política agraria como base de la autarquía económica y la evolución de los tipos urbanos volvió a depender de la preocupación higienista, incorporando sólo mejoras como el abandono de segundas luces. La inflexión vino en 1944, aprobándose los primeros parámetros mínimos cuantificables aplicables en todo régimen de viviendas, cambio que supuso entrar en la dinámica de las actuales normativas y la aparición de los primeros tipos residenciales que pueden considerarse modernos y actuales.

La calificación de "Viviendas Bonificables" trató de activar el volumen de construcción, pero fue el sistema de "Viviendas de Renta Limitada", coincidiendo con la redacción de la Ley del Suelo (1956) para evitar la especulación, el que aumentó sin precedentes el parque de viviendas accesibles. A partir de entonces, los Planes Generales y el Ministerio de la Vivienda dieron paso a un nuevo periodo "desarrollista", aunque en la primera mitad de la década de los cincuenta, los primeros ejemplos residenciales en esta línea ya se habían anticipado.

La reflexión que puede deducirse, y que se constata en el estudio de Benalúa, evidencia la vivienda como un problema secundario, tangencial o subordinado de las políticas de trabajo o del propio negocio y mantenimiento de la construcción.
Confirma un comportamiento altamente permisivo para el sector privado por parte del Estado, aunque no ajeno al contexto social ni a su evolución en el transcurso del tiempo. Como consecuencia descubrimos una interesante relación entre contexto social y desarrollo normativo, expresión del modelo de ciudad que da cuenta de los valores de la sociedad que alberga, si bien más allá de su intención o planteamiento teórico no se advierten compromisos o garantías de cumplimiento. Este hecho explica tanto la influencia puntual que tuvo la normativa estatal en los tipos edificatorios, como también su importancia determinante y definitoria en la evolución tipológica, precisamente por intervenir en situaciones de extrema necesidad y conflicto social, conllevando siempre transformaciones sustanciales.

\section{Bibliografía}

ALONSO SALVADOR, Matilde; BLASCO SÁNCHEZ, Carmen y PIÑON Pallarés, Juan Luis. Alicante: V siglos de arquitectura. Alicante, España, Colegio Oficial de Arquitectos de la Comunidad Valenciana, Demarcación de Alicante. 1990. 112 p. ISBN 84-600-7505-2.

ARCHIVO Histórico Municipal de Alicante. Expediente barrio de Benalúa. Obras Particulares, signatura 9999-12-42. 1884.

ARIAS GONZÁLEZ, Luis. Socialismo y vivienda obrera en España (1926-1939). Salamanca, España, 
Ediciones Universidad de Salamanca. 2003. 334 p. ISBN 84-7800-797-0. Colección estudios históricos y geográficos 120 .

AYUNTAMIENTO de Alicante. Reglamento para la higiene y salubridad de la ciudad de Alicante. Alicante, España, Tipografía Such Serra y $C^{a}$. 1913.

BELMÁS Estrada, Mariano. Construcciones económicas y casas para obreros. Madrid, España, Imprenta de Enrique Teodoro. 1883

-.-- Medios para dar solución al problema de las construcciones económicas: conferencia dada en el Fomento de las Artes, el día 15 de abril de 1882. Madrid, España, Establecimiento tipográfico de Sucesores de Rivadeneyra. 1882.

---- Las construcciones económicas del Sistema Belmás, bajo los puntos de vista social, constructivo y económico: conferencia dada en el Fomento de las Artes, el día 16 de abril de 1881. Madrid, España, Imprenta y Estereotipia de Aribau y $\mathrm{C}^{\mathrm{a}}$. 1881.

BEVIÀ GARCÍA, Màrius y VARELA BOTELLA, Santiago. Alicante: ciudad y arquitectura. Alicante, España, Fundación Cultural Caja de Ahorros del Mediterráneo CAM. 1994. 244 p. ISBN 84-7599-146-7.

CABELLO LAPIEDRA, Luis María. Habitaciones obreras: datos relativos a su desarrollo y progreso. $\mathrm{La}$ Construcción moderna. Revista quincenal de Arquitectura e Ingeniería. 1(23): 505-508. Diciembre 1903. ISSN 1889-8408.
CALDUCH CERVERA, Juan. La ciudad Nueva, la construcción de la ciudad de Alicante en la primera mitad del siglo XIX. Alicante, España, Patronato Municipal del Quinto Centenario de la Ciudad de Alicante. 1990. 178 p. ISBN 84-505-9379-4.

CALDUCH CERVERA, Juan y VARELA BOTELLA, Santiago. Guía de arquitectura de Alacant. Alicante, España, Comisión de Publicaciones del CSI del Colegio de Arquitectos de Alicante. 1979. Tomo $1,166 \mathrm{p}$.

CALLE VELASC0, María Dolores de la. Sobre los orígenes del Estado social en España. Ayer. (25): 127150. 1997. ISSN 1134-2277.

---- La Comisión de Reformas Sociales: de la represión al análisis de la conflictividad social. [En línea]. Studia histórica. Historia contemporánea. 2: 13-40. 1984. ISSN 0213-2087. Disponible en: http://campus.usal.es/ revistas_trabajo/index. php/0213-2087/article/view/5688.

CANDAU PÉREZ, Margarita. Acercarse a la política de vivienda en la provincia de Valladolid: el fondo documental de la Delegación Provincial del Ministerio de la Vivienda del Archivo Histórico Provincial de Valladolid. Investigaciones Históricas: época moderna y contemporánea. (25): 265-280, 2005. ISSN 0210-9425.

CASALI, I. 125 modelos de edificios económicos. Casas baratas, villas y granjas. Barcelona, España, Gustavo Gili. 1915. 424 p.

CASAS DE BATISTA, Rogelio. El problema relativo al hogar obrero. En: Discursos pronunciados en la

revista invi ํㅜ 78 / Agosto 2013 / Volumen N² 28: 221-255 251 
Academia de Medicina de Madrid para la recepción pública del académico electo D. Rogelio Casas de Batista, el día 11 de enero de 1874. Madrid, España. 1874. 106 p.

CASTRILLO ROMóN, María Ángeles. Influencias europeas sobre la "Ley de Casas Baratas" de 1911: el referente de la "Loi des Habitations à Bon Marché" de 1894. Cuadernos de investigación urbanistica. (36): 5-52, noviembre 2003. ISSN 1886-6654.

---- Reformismo, vivienda y ciudad. Orígenes y desarrollo del debate en España 1850-1920. Valladolid, España, Universidad de Valladolid. 2001. 405 p. ISBN 84-8448-118-2. Colección Arquitectura y Urbanismo 38.

CERDÁ SUÑER, Ildefonso. Teoría de la construcción de las ciudades aplicada al Proyecto de Reforma y Ensanche de Barcelona. Ed. facsímil de 1859. En: Teoría de la construcción de las ciudades: Cerdà y Barcelona (vol. 1). Madrid, España, Instituto Nacional de la Administración Pública y Ajuntament de Barcelona. 1991. ISBN 84-7088-583-9.

---- Teoría general de la urbanización y aplicación de sus principios y doctrinas a la Reforma y Ensanche de Barcelona (Tomo I). Ed. facsímil de 1867. Madrid, España, Centro de Estudios Políticos y Constitucionales. 1968. ISBN 84-259-0071-9.

FERNÁNDEZ DE LOS RÍOS, Ángel. El futuro Madrid, paseos mentales por la capital de España, tal cual es y tal cual debe dejarla transformada la revolución. Ed. facsímil de 1868. Barcelona, España, José Batlló, Editor. 1975. 480 p. Los libros de la frontera. ISBN 84-377-0024-8.
GARCÍA ANTÓN, Irene. La arquitectura de principios de siglo en Alicante y Provincia. Alicante, España, Excma. Diputación de Alicante. 1980. 208 p. ISBN 84-500-3858-8.

GIMÉNEZ GARCÍA, Efigenio; GINER ÁLVAREZ, Jaume y VARELA BOTELLA, Santiago. Sobre la ciudad dibujada de Alicante, del plano geométrico al plan general de 1970. Alicante, España, Colegio Oficial de Arquitectos de Valencia, Delegación de Alicante, Alicante. 1985. 60 p. ISBN 505-1652-8.

GONZÁLEZ ORDOVÁS, María José. Políticas y estrategias urbanas. Madrid, España, Fundamentos. 2000. 320 p. ISBN 84-245-0836-X. Colección Ciencia 236. Serie Política y Sociología.

GUARDIOLA PICÓ, José. Reformas en Alicante para el siglo XX, Tercera parte. Alicante, España, Imprenta Luis Esplá. 1909.

---- Alicante en el siglo venidero. Alicante, España, Imprenta Galdó Chápuli. 1897.

---- Reformas en Alicante para el siglo XX. Alicante, España, Imprenta Juan José Carratalá. 1895.

HALL, Peter. Ciudades del mañana: Historia del urbanismo en el siglo XX. Barcelona, España, Ediciones del Serbal. 1996. 496 p. ISBN 84-7628-190-0. Colección La estrella polar.

HUERTAS GARCíA-ALEJO, Rafael. Política sanitaria: de la Dictadura de Primo de Rivera a la II $^{\mathrm{a}}$ República. [En línea]. Revista Española de Salud Pública. 74: 35-43, 2000. ISSN 1135-5727. Disponible en: http://dx.doi.org/10.1590/ S1135-57272000000600004. 
INSTITUTO de Reformas Sociales. Preparación de las bases para un proyecto de ley de casas para obreros, Casas Baratas. Madrid, España, Imprenta de M. Servet. 1910. 2 t, 744 p, 222 p.

JEFATURA DEL ESTADO. Decreto-Ley de 25 de febrero de 1957. Boletín Oficial del Estado. 22(57): 1231, febrero 1957.

---- Ley de 12 de mayo de 1956. Boletín Oficial del Estado. 21(135): 3106-3134, mayo 1956.

---- Ley de 15 de julio de 1954. Boletín Oficial del Estado. 19(197): 4834-4841, julio 1954.

---- Decreto-Ley de 19 de noviembre de 1948. Boletín Oficial del Estado. 13(348): 5570-5573, Diciembre 1948.

---- Ley de 31 de diciembre de 1946. Boletín Oficial del Estado. 12(1): 82-110, enero 1947.

---- Ley de 25 de noviembre de 1944. Boletín Oficial del Estado. 9(332): 8959-8964, noviembre 1944.

---- Ley de 19 de abril de 1939. Boletín Oficial del Estado. 4(110): 2190-2198, abril 1939.

MARTÍNEZ MEDINA, Andrés. La arquitectura de la ciudad de Alicante 1923-1943, la aventura de la modernidad. Alicante, España, Instituto de Cultura Juan Gil-Albert. 1998. 428 p. ISBN 84-7784-304-X.

MINISTERIO de la Gobernación. Orden de 29 de febrero de 1944. Boletín Oficial del Estado. 9(61): 18331834, marzo 1944.

---- Orden de 16 de septiembre de 1943. Boletín Oficial del Estado. 8(261): 9044, septiembre 1943.
---- Real Orden de 9 de agosto de 1923. Gaceta de Madrid. 262(228): 821-823, agosto 1923b.

---- Real Orden de 3 de enero de 1923. Gaceta de Madrid. 262(10): 132-140, enero 1923a.

---- Real Decreto de 11 de abril de 1912. Gaceta de Madrid. 251(106): 101-110, abril 1912.

---- Ley de 12 de junio de 1911. Gaceta de Madrid. 250(164): 755-758, junio 1911.

---- Real Decreto de 15 de agosto de 1903. Gaceta de Madrid. 242(230): 1970-1973, agosto 1903.

---- Real Decreto de 18 de marzo de 1895. Gaceta de Madrid. 234(80): 1043-1045, marzo 1895.

---- Real Decreto de 13 de mayo de 1890. Gaceta de Madrid. 229(134): 426-427, mayo 1890.

---- Real Decreto de 7 de diciembre de 1883. Gaceta de Madrid. 222(344): 761-763, diciembre 1883.

MINISTERIO de Organización y Acción Sindical. Decreto de 13 de octubre de 1938. Boletín Oficial del Estado. 3(116): 1976-1977, octubre 1938.

MINISTERIO de Trabajo. Orden de 12 de julio de 1955. Boletín Oficial del Estado. 20(197): 4319-4321, julio 1955c.

---- Decreto de 1 de julio de 1955. Boletín Oficial del Estado. 20(197): 4314-4315, julio 1955b.

---- Decreto de 24 de junio de 1955. Boletín Oficial del Estado. 20(197): 4301-4314, julio 1955a.

---- Decreto de 8 de septiembre de 1939. Boletín Oficial del Estado. 4(275): 5506-5516, octubre 1939.

revista invi ํำ 78 / Agosto 2013 / Volumen N² 28: 221-255 253 
---- Ley de 10 de diciembre de 1921. Gaceta de Madrid. 260(345): 858-866, diciembre 1921.

---- Orden de 7 de febrero de 1945. Boletín Oficial del Estado. 10(42): 1221-1226, febrero 1945.

MINISTERIO de Trabajo, Comercio e Industria. Real Decreto de 3 de julio de 1922. Gaceta de Madrid. 261(209): 363-399, julio 1922.

MINISTERIO de Trabajo, Sanidad y Previsión. Ley de 25 de junio de 1935. Gaceta de Madrid. 274(177): 2442-2446, junio 1935.

MINISTERIO de Trabajo y Previsión. Orden de 30 de junio de 1933. Gaceta de Madrid. Año 273(194): 287, junio 1933.

---- Decreto de 18 de julio de 1931. Gaceta de Madrid. 270(200): 567-568, julio 1931a.

---- Orden de 5 de octubre de 1931. Gaceta de Madrid. 270(280): 136-139, octubre 1931b.

PÉREZ DEL HOYO, Raquel. El Barrio Benalúa de Alicante: análisis de su formación, consolidación y transformación a partir del estudio de su documentación gráfica (1883-1956). España, Departamento de Expresión Gráfica y Cartografía, Universidad de Alicante. 2010. 931 p. Tesis doctoral en arquitectura.

PONCE HERRERO, Gabino y DÁVILA LINARES, Juan Manuel. Medidas higienistas y planes de reforma urbana en el tránsito de los siglos XIX al $\mathrm{XX}$ en las principales ciudades de la provincia de Alicante. [En línea]. Investigaciones Geográficas. (20): 141-159, 1998. ISSN 0213-4691.
Disponible en: http://rua.ua.es/dspace/bitstream/10045/420/1/Ponce\%20Herrero-Medidas\%20higienistas.pdf.

PRESIDENCIA del Consejo de Ministros. Real Decreto de 8 de mayo de 1920. Gaceta de Madrid. 259(130): 539, mayo 1920.

-.-- Real Decreto de 23 de abril de 1903. Gaceta de Madrid. 242(120): 371-372, abril 1903.

PRESIDENCIA del Directorio Militar. Real Decreto de 9 de febrero de 1925. Gaceta de Madrid. 264(48): 726-733, febrero 1925.

---- Real Decreto Ley de 10 de octubre de 1924. Gaceta de Madrid. 263(289): 258-265. Octubre 1924.

REBOLLEDO PALMA, José Antonio. Casas para obreros o económicas. Madrid, España, Imprenta de la Viuda e hijos de Galiano. 1872. 128 p.

REPULLÉS VARGAS, Enrique María. Los barrios de obreros. Resumen de Arquitectura. 1: 65-67, septiembre 1891. ISSN 2171-3006.

SAMBRICIO RIBERA DE ECHEGARAY, Carlos. Madrid, vivienda y urbanismo: 1900-1960. Madrid, España, Akal. 2004. 444 p. ISBN 84-460-1990-6. Colección Arquitectura 28.

---- De la arquitectura del nuevo estado al origen de nuestra contemporaneidad: el debate sobre la vivienda en la década de los cincuenta. Revista de Arquitectura. (4): 75-90. 2000. ISSN $1138-5596$.

SOCIEDAD Central de Arquitectos. Leemos en un colega: Sociedad constructora. Revista de la Sociedad 
Central de Arquitectos. 12: 152. 10 de julio de 1885 ISSN 2171-2999.

---- Casas para obreros. Revista de la Sociedad Central de Arquitectos. 10: 270-271, diciembre 1883c. ISSN 2171-2999.

---- La cuestión obrera. Revista de la Sociedad Central de Arquitectos. 9: 223-224, diciembre 1882. ISSN 2171-2999.

---- La Habitación. Revista de la Sociedad Central de Arquitectos. 10: 96, abril 1883b. ISSN 2171-2999.

---- Sesiones del Congreso Nacional de Arquitectos celebrado en Madrid en mayo de 1881 por iniciativa de la Sociedad Central y documentos referentes al mismo. Madrid, España, Establecimiento tipográfico de Gregorio Juste. 1883a. $288 \mathrm{p}$.
SORIA MATA, Arturo. La cuestión social y la Ciudad Lineal. Diario El Progreso. Madrid, España. 5 de marzo de 1883.

---- La ciudad lineal. Diario El Progreso. Madrid, España. 10 de abril de 1882 .

---- Madrid remendado y Madrid nuevo. Diario El Progreso. Madrid, España. 6 de marzo de 1882.

TERÁN TROYANO, Fernando de. Planeamiento urbano en la España contemporánea (1900/1980). Madrid, España, Alianza. 1982. 635 p. ISBN 84-206-8039-7.

-.-- Revisión de la ciudad lineal: Arturo Soria. Arquitectura. 72: 3-20, diciembre 1964. ISSN 0004-2706.

VARELA BOTELLA, Santiago. Benalúa o el centenario de un barrio. Diario Información. 22 de marzo de 1984. 


\section{OPINIÓN / OPINION}

